\title{
Features of the seasonal variation of the semidiurnal, terdiurnal and 6-h components of ozone heating evaluated from Aura/MLS observations
}

\author{
J. Xu' ${ }^{1}$, A. K. Smith ${ }^{2}$, G. Jiang ${ }^{1}$, W. Yuan ${ }^{1}$, and H. Gao ${ }^{1}$ \\ ${ }^{1}$ State Key Laboratory of Space Weather, Center for Space Science and Applied Research, Chinese Academy of Sciences, \\ Beijing, China \\ ${ }^{2}$ Atmospheric Chemistry Division, National Center for Atmospheric Research, Boulder, CO, USA \\ Correspondence to: J. Xu (xujy@nssc.ac.cn)
}

Received: 5 December 2011 - Revised: 19 January 2012 - Accepted: 19 January 2012 - Published: 1 February 2012

\begin{abstract}
This paper presents the thermal forcing of the semidiurnal, terdiurnal, and 6-h components of the migrating tide induced by ozone heating in stratosphere and lower mesosphere. The heating as a function of local time is determined from the global ozone observed by the Microwave Limb Sounder on the Aura satellite. The harmonic components of the heating rates of the semidiurnal, terdiurnal and the 6-h periodicities are calculated using the Strobel/Zhu parameterized model and then decomposed into Hough modes. Seasonal variations of each harmonic component and its Hough modes are presented. For all three tidal components, the majority of the annual mean $\mathrm{O}_{3}$ heating projects onto symmetric modes. The semiannual variation is a prominent signal in almost all of the symmetric Hough modes near the stratopause. The strongest annual variation takes place in the asymmetric modes. The results also show that, during the solstice season, the maximum forcing of the diurnal and terdiurnal component occurs in the summer hemisphere while the maximum forcing of the semidiurnal and 6-h components occurs in the winter hemisphere. The global mean ozone density and the tidal components of the ozone heating rate are different between December-January and June-July. The asymmetry in the heating is primarily due to the $6.6 \%$ annual variation in the solar energy input into the Earth's atmosphere due to the annual variation of the Sun-Earth distance.
\end{abstract}

Keywords. Atmospheric composition and structure (Middle atmosphere - composition and chemistry) - Meteorology and atmospheric dynamics (Middle atmosphere dynamics; Waves and tides)

\section{Introduction}

Atmospheric tides are waves for which the periods are harmonics of a day: $24 \mathrm{~h}, 12 \mathrm{~h}, 8 \mathrm{~h}, 6 \mathrm{~h}$, etc. The bulk of the tidal forcing is thermal but other processes can also generate waves at tidal periods. The source of the heating that excites the tides is absorption of solar radiation by $\mathrm{O}_{2}$ and $\mathrm{N}_{2}$ in the lower thermosphere, ozone in the stratosphere, and water vapor in the troposphere. Latent heat release in the troposphere also contributes.

The diurnal and semidiurnal tides have been extensively studied, for example by Forbes and Garrett (1979) and Groves (1982). In a recent study Xu et al. (2010) used the parameterization of Strobel (1978) and Zhu (1994) to determine the 24-h (diurnal) harmonic of the ozone heating in the stratosphere and lower mesosphere. They also determined the annual, semiannual, and even $\mathrm{QBO}$ variations of the heating rates and their Hough mode decompositions.

Higher frequency tidal modes have not been investigated as thoroughly. The excitation mechanism of the terdiurnal tide is still an open question. Groves and Wilson (1982) briefly discussed the Hough modes of the terdiurnal components of ozone heating for four midseason months (January, April, July and October). Mechanisms of excitation of the terdiurnal tide that have been proposed include the excitation by direct solar heating in the troposphere and stratosphere (e.g. Chapman and Lindzen, 1970), non-linear interaction between the 24- and 12-h tides (e.g. Teitelbaum et al., 1989; Smith, 2000), and non-linear interaction between the 24-h tide and gravity waves (e.g. Miyahara and Forbes, 1991). 
Simulations (Smith and Ortland, 2001; Akmaev, 2001) indicate that the direct solar forcing of the terdiurnal tide is the dominant mechanism occurring at middle and high latitudes. Nonlinear interactions contribute to the low-latitude tide (Smith and Ortland, 2001), and at equinox when the diurnal tide reaches maximum amplitudes (Akmaev, 2001). Simulations (Smith et al., 2004) indicate that solar heating is also the primary mechanism for forcing the 6-h tide.

In this paper, we use the same data and the same analysis method of $\mathrm{Xu}$ et al. (2010) to determine the seasonal variations of the semidiurnal, terdiurnal, and 6-h tidal components of the ozone heating rate in stratosphere and lower mesosphere. Data from the Microwave Limb Sounder (MLS) instrument on the Aura satellite was chosen for the analysis because of its near-global coverage, necessary for the Hough mode analysis. MLS has been providing continuous observations of the temperature, ozone, and other chemical species over the latitude range $82^{\circ} \mathrm{S}$ to $82^{\circ} \mathrm{N}$ since August 2004 . MLS ozone profiles extend from $10 \mathrm{~km}$ to above $70 \mathrm{~km}$.

Section 2 describes the analysis for calculating the heating rate, its harmonic components, its Hough mode decomposition and its seasonal variations. Section 3 describes the general features of seasonal variations of the diurnal, semidiurnal, terdiurnal, and 6-h tidal components of the ozone heating rate. Sections 4, 5 and 6 present the seasonal variations in the semidiurnal, terdiurnal, and 6-h components of the heating rate and their respective Hough modes. A summary is given in Sect. 6.

\section{Analysis of the harmonic components and Hough modes of the heating rate}

\subsection{Data set}

MLS (Microwave Limb Sounder) on the Sun-synchronous NASA Aura satellite began atmospheric observations on 13 August 2004. MLS measures ozone, temperature and other chemical species from 215 to $0.02 \mathrm{hPa}$, about 10 to $75 \mathrm{~km}$, with a vertical resolution of about $3 \mathrm{~km}$. In this paper, we use Aura/MLS Level 2 Version 2.2 temperature and ozone data from August 2004 to November 2010. The times of daily observations are centered at two local times, near midday and midnight. Only daytime values are used since the total ozone heating is approximately a box function with maximum centered at midday and zero heating at night.

\subsection{Calculation method and process}

The calculation method is described in detail by $\mathrm{Xu}$ et al. (2010). Key points are summarized here. The calculation includes five steps:

\section{First step: gridding the data}

Each daytime ozone vertical profile is interpolated to a uniform vertical grid with $1 \mathrm{~km}$ spacing from $10 \mathrm{~km}$ to $75 \mathrm{~km}$. The profiles are sorted into overlapping latitude bins that are $10^{\circ}$ wide with centers offset by $5^{\circ}$, extending from $80^{\circ} \mathrm{S}$ to $80^{\circ} \mathrm{N}$. The daytime ozone profiles are averaged for each day and latitude bin at all longitudes. This step selects the ozone distribution that contributes to forcing the migrating tides and removes any potential non-migrating tidal signals.

\section{Second step: calculation of the diurnal variation of ozone heating}

The ozone heating rate is calculated using the parameterization of Strobel (1978) and the improvement on the parameterization made by Zhu (1994). This heating parameterization is referred to as the Strobel/Zhu model. As pointed out by $\mathrm{Xu}$ et al. (2010), this parameterized model gives an incomplete determination of heating in the upper mesosphere where absorption of solar radiation is not immediately converted to heat but the heating is well represented over the altitude range investigated here. Xu et al. (2010) compared the MLS midday ozone to the full diurnal variations of ozone observed by TIMED/SABER. They found that the midday ozone concentrations observed by MLS are representative of all daytime hours since the ozone mixing ratio in this altitude range is almost constant during the daytime.

We divide each day into 60 local time points with a step of $24 / 60 \mathrm{~h}$. The heating rate for each local time and latitude bin for each day is then calculated. The calculation uses the average ozone profiles described above and the diurnal variation of solar zenith angle for the specific latitude and day of year. The calculation also accounts for the annual variation of the Sun-Earth distance. During the year, the energy input to the top of the atmosphere varies by $6.6 \%$; the maximum is in January and the minimum in July. Solar variability due to the 11-year cycle or shorter term variations is not included.

\section{Third step: decomposing the heating into harmonic components}

In the harmonic decomposition of the global heating rate, we include the daily mean and the 24-h, 12-h, 8-h and 6-h periods. At each day number $d$, altitude $z$, and latitude $\theta$, the heating from these components can be expressed as

$$
\begin{aligned}
q(d, \theta, z, t)= & Q_{0}(d, \theta, z)+\sum_{m=1}^{4}\left[Q_{m}^{c}(d, \theta, z) \cos \left(m \omega_{0} t\right)\right. \\
& \left.+Q_{m}^{s}(d, \theta, z) \sin \left(m \omega_{0} t\right)\right]
\end{aligned}
$$

$\omega_{0}=2 \pi / 24(\mathrm{~h})$ is the frequency of the diurnal tide, $t$ is the local time, $Q_{0}$ is the daily mean heating rate, and $m=$ 1,2,3,4 correspond to 24-h, 12-h, 8-h and 6-h tides, respectively. The tidal components of the ozone heating are 

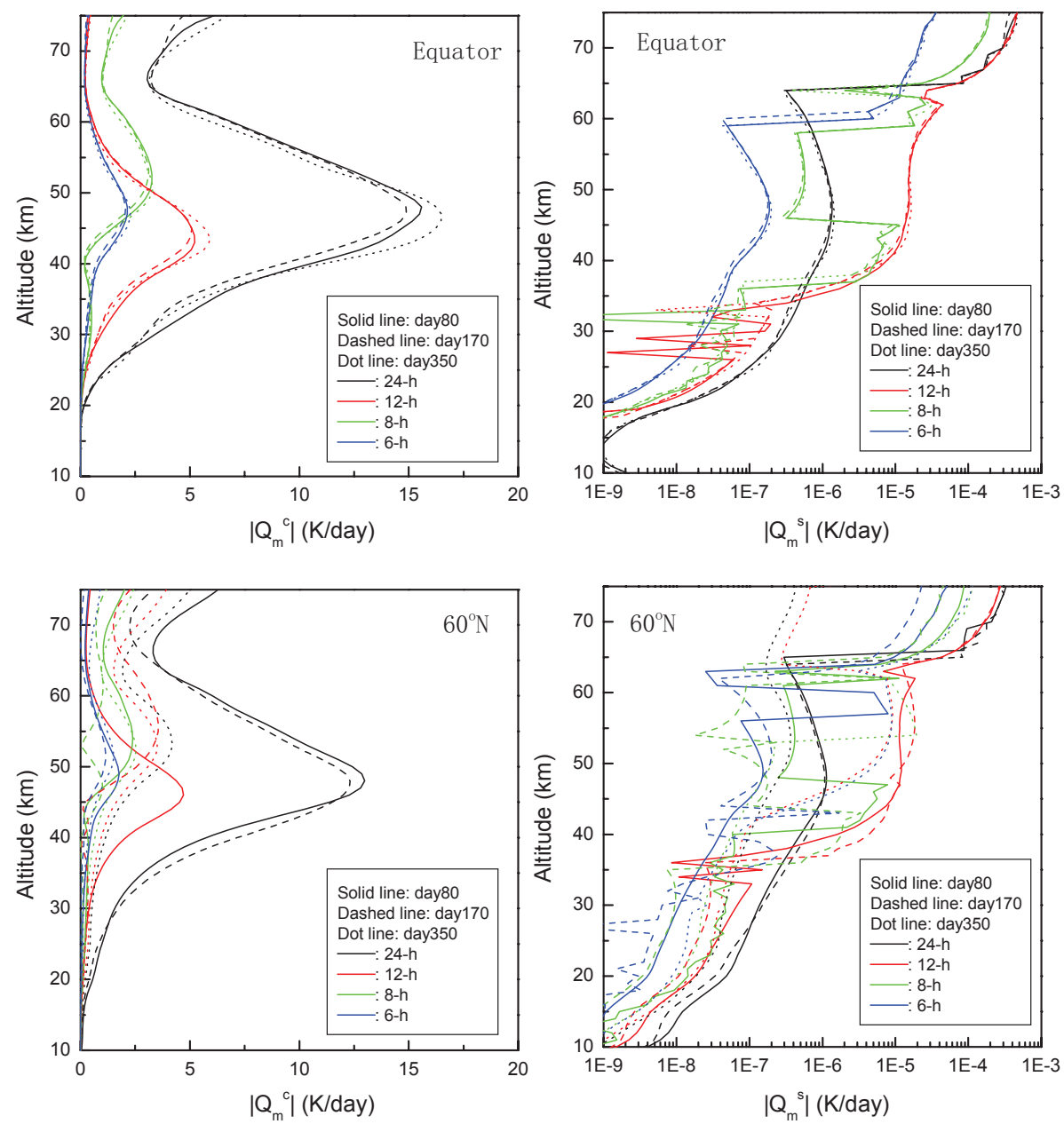

Fig. 1. Vertical profiles of the absolute values of the coefficients of the cosine (left) and sine (right) terms of the ozone heating rate tidal components for day 80, day 170 , and day 350 in 2005.

represented by two terms, $Q_{m}^{c}$ and $Q_{m}^{s}$. Figure 1 shows the absolute values of $\left|Q_{m}^{c}\right|$ and $\left|Q_{m}^{s}\right|$ at the equator and $60^{\circ} \mathrm{N}$ for March equinox and the June and December solstices. The values of $\left|Q_{m}^{s}\right|$ are 4 orders of magnitude smaller than $\left|Q_{m}^{c}\right|$ for all four tidal components in the stratosphere and lower mesosphere. This is because the ozone heating rate reaches maximum around 12:00 LT and minimum around 00:00 LT, which projects on to a cosine of local time. The heating rate is nearly symmetric around the local times of 00:00 or 12:00. Since the sine function is asymmetric relative to the local times of 00:00 or 12:00, its magnitude $\left|Q_{m}^{s}\right|$ is very small. Analysis for other latitudes and seasons verifies that $Q_{m}^{s}$ is small globally and so $Q_{m}^{s}$ is omitted in the remainder of the analysis. The heating rate can be simplified to:

$q(d, \theta, z, t)=Q_{0}(d, \theta, z)+\sum_{m=1}^{4} Q_{m}(d, \theta, z) \cos \left(m \omega_{0} t\right)$

where the superscript $\mathrm{c}$ is omitted for simplification. Note that the sign of $Q_{m}(d, \theta, z)$ is positive when the phase (the hour at which this component in the heating rate reaches maximum) is zero and is negative when the phase is nonzero. A phase of zero indicates a midnight maximum and a nonzero phase indicates a midnight minimum. In this paper, we use the word "coefficient", which includes the information on amplitude and phase, to describe each harmonic mode.

\section{Fourth step: decomposing into Hough modes}

The Hough functions for each tidal component form a complete orthogonal set extending from pole to pole. For decomposition, the heating rates are needed over the full latitudinal range. The heating rates determined from MLS must therefore be extended from $80^{\circ}$ to the pole in both hemispheres. Since the heating rates at sub-harmonics of a solar day should be zero at the poles, the heating rates between $80^{\circ} \mathrm{S}$ and $90^{\circ} \mathrm{S}$ and between $80^{\circ} \mathrm{N}$ and $90^{\circ} \mathrm{N}$ are calculated by interpolation. 

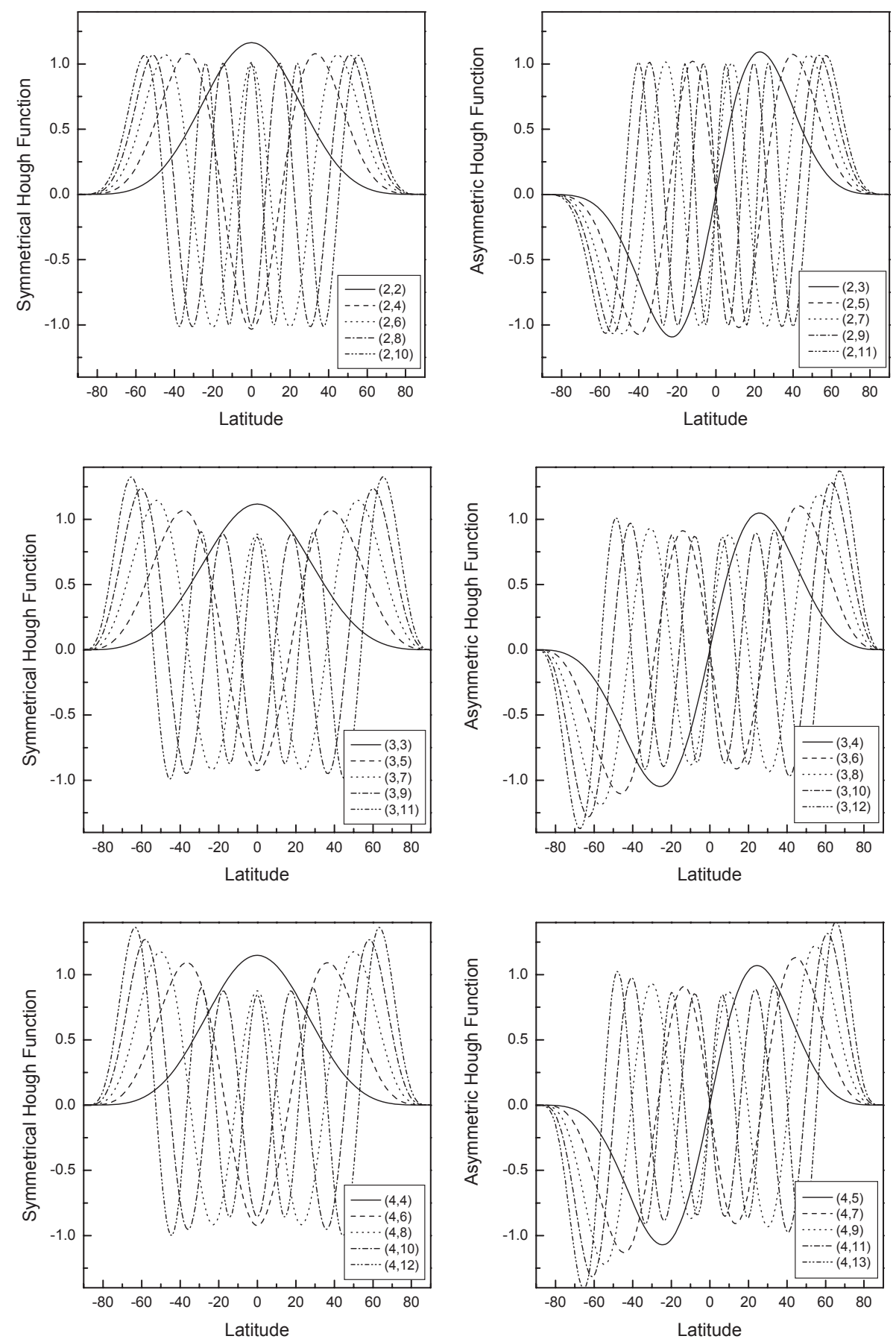

Fig. 2. The first 10 normalized Hough functions for the semidiurnal (upper panel), terdiurnal (middle panel), and 6-h (lower panel) modes. Left panels: symmetric functions; right panels: asymmetric functions.

For each tidal component of the heating rate, the local time dependence is given by the coefficient $Q_{m}(d, \theta, z)$, where $m=1,2,3$, and 4 correspond to $24-\mathrm{h}, 12-\mathrm{h}, 8-\mathrm{h}$, and $6-\mathrm{h}$ periods, respectively). The $m$-th tidal component of the global heating rate is then expanded in terms of normalized Hough function, $\Theta_{m, n}(\theta)$ :

$$
\begin{aligned}
& Q_{m}(d, \theta, z)=\sum_{n} \alpha_{m, n}(d, z) \Theta_{m, n}(\theta), \\
& \alpha_{m, n}(d, z)=\int_{-90^{\circ}}^{90^{\circ}} Q_{m}(d, \theta, z) \Theta_{m, n}(\theta) \cos (\theta) d \theta .
\end{aligned}
$$


The orthogonal and normalized conditions are:

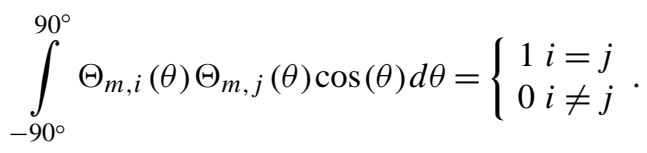

$\alpha_{m, n}(d, z)$ is the coefficient of the $n$-th component of the Hough modes for the $m$-th tidal component of the heating rate.

The Hough coefficients in Eq. (3b) depend on the signs of the Hough modes. Signs are chosen so that each Hough function increases with latitude away from the North Pole. The Hough functions of the semidiurnal, terdiurnal, and 6-h components are shown in Fig. 2. Using Eq. (3), the heating rate of the $m$-th tidal component can be written:

$q_{m}(d, \theta, z, t)=\sum_{n} \alpha_{m, n}(d, z) \Theta_{m, n}(\theta) \cos \left(m \omega_{0} t\right)$

\section{Fifth step: seasonal variations}

In this step, we calculate the annual (AO), semiannual (SAO), and quasi-biennial (QBO) oscillations in the net tidal ozone heating and in the coefficients of each Hough mode using the heating from August 2004 to November 2010. The relative contributions of the periodic variations in the diurnal, semidiurnal, terdiurnal, and 6-h components in the ozone heating rate to the net variability are also determined. We express the long-term variations of the amplitudes of the diurnal, semidiurnal, terdiurnal, and 6-h components in the ozone heating as the sum of the $\mathrm{SAO}, \mathrm{AO}$, and $\mathrm{QBO}$ variations and a linear trend:

$$
\begin{aligned}
f= & \bar{f}+\mu\left(d-d_{\mathrm{c}}\right)+f_{\mathrm{SAO}} \cos \left[\frac{2 \pi}{182.5(\text { day })}\left(d-d_{\mathrm{SAO}}\right)\right] \\
& +f_{\mathrm{AO}} \cos \left[\frac{2 \pi}{365 \text { (day) }}\left(d-d_{\mathrm{AO}}\right)\right] \\
& +f_{\mathrm{QBO}} \cos \left[\frac{2 \pi}{P_{\mathrm{QBO}}(\text { day })}\left(d-d_{\mathrm{QBO}}\right)\right] .
\end{aligned}
$$

$\bar{f}$ is the average value of parameter $f$ over the period August 2004-November 2010. $\mu$ is the trend in $f$ over this period. $d_{\mathrm{c}}$ is the central day of the 6 year observation period. $f_{\mathrm{SAO}}, f_{\mathrm{AO}}$, and $f_{\mathrm{QBO}}$ are the amplitudes of the $\mathrm{SAO}$, $\mathrm{AO}$ and $\mathrm{QBO}$ in $f$ over this period. $d_{\mathrm{SAO}}, d_{\mathrm{AO}}$, and $d_{\mathrm{QBO}}$ are the phases of the three oscillations. Generally speaking, the period of the QBO in lower stratospheric winds in the equatorial region is variable within the range 18-34 months. Therefore, the period of the $\mathrm{QBO}$ is also a variable, $P_{\mathrm{QBO}}$. The trend and the $\mathrm{SAO}, \mathrm{AO}$ and $\mathrm{QBO}$ in the parameter $f$ are determined simultaneously using a nonlinear least squares fitting method. In this analysis, we solve for the optimal period of the QBO within the range 18-34 months to get minimum error of the fitting during the period from August 2004 to November 2010. The method used to quantify the seasonal and longer-term variability of the parameter $f$ is similar to that used in the temperature and diurnal component in ozone heating analysis in Xu et al. (2007, 2009, 2010); see those papers for more detail.

\section{The distribution of the harmonic components of ozone heating}

Figure 1 shows that the peaks of the daily mean heating rate and the harmonic components of the heating rate at the equator are near the stratopause (see also Fig. 2 in Xu et al., 2010). Taking $50 \mathrm{~km}$ as an example, we show the latitudinal distributions of the daily mean heating rate and the coefficients of the diurnal, semidiurnal, terdiurnal, and 6-h components in the ozone heating rate over the period from August 2004 to November 2010 in Fig. 3. The daily mean ozone heating rate (Fig. 3a) is about $16 \mathrm{~K} \mathrm{day}^{-1}$ at the summer polar region, where it is polar day ( $24 \mathrm{~h}$ of sunlight). Figure $3 \mathrm{~b}$ shows that the diurnal component is negative for all seasons and all latitudes, indicating that the phase (at which the heating rate reaches maximum) of the diurnal component of heating rate is around 12:00 LT. The heating in the diurnal component is stronger in the summer hemisphere than in the winter hemisphere. The latitude of the maximum heating rate moves between $30^{\circ} \mathrm{S}$ and $30^{\circ} \mathrm{N}$.

The coefficient of the semidiurnal component of the heating rate (Fig. 3c) is negative in the high latitudes of the summer hemisphere and is most strongly positive in the middle latitudes of the winter hemisphere. A positive sign for a semidiurnal oscillation indicates heating maxima at noon and midnight while a negative sign indicates minima (i.e. maxima at 06:00 LT and 18:00 LT). Figure $3 \mathrm{~d}$ shows that the coefficient of the terdiurnal component reaches its most positive maximum in the middle latitudes of the summer hemisphere. Its largest negative value is seen in high latitudes of the winter hemisphere. For the 6-h component (Fig. 3e), the strongest forcing is a negative value that occurs around the latitude of $30^{\circ}$ in the winter hemisphere. Around $50^{\circ}$ in the summer hemisphere, there is a second positive peak.

From Fig. 3 we can see that annual oscillations (AO) dominate the seasonal variation of these five components. It is interesting that the daily mean, diurnal and terdiurnal components of the heating rate have their largest magnitudes in the summer hemisphere while the semidiurnal and 6-h components of the ozone heating have their largest magnitudes in the winter hemisphere. From Fig. 3, we can also see that the daily mean heating at high latitudes has a dominant annual cycle but all of the tidal heating components have obvious semi-annual oscillation (SAO) signatures in high latitudes of both hemispheres.

On the other hand, there is no obvious QBO in the harmonic components shown in Fig. 3. Observations show that there is a robust $\mathrm{QBO}$ variation in ozone in the tropical lower stratospheric range of 20-30 km (e.g. Randel and Wu, 1996; Baldwin et al., 2001; Logan et al., 2003; Schoeberl et al., 2008). The harmonic decomposition of the ozone heating at 
(a) Daily mean ozone heating rate
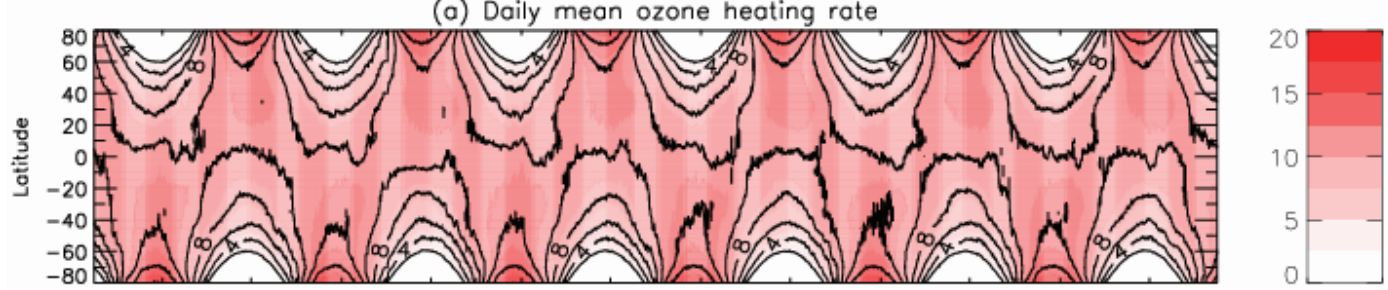

(b) Coefficient of diurnal (24h) heating
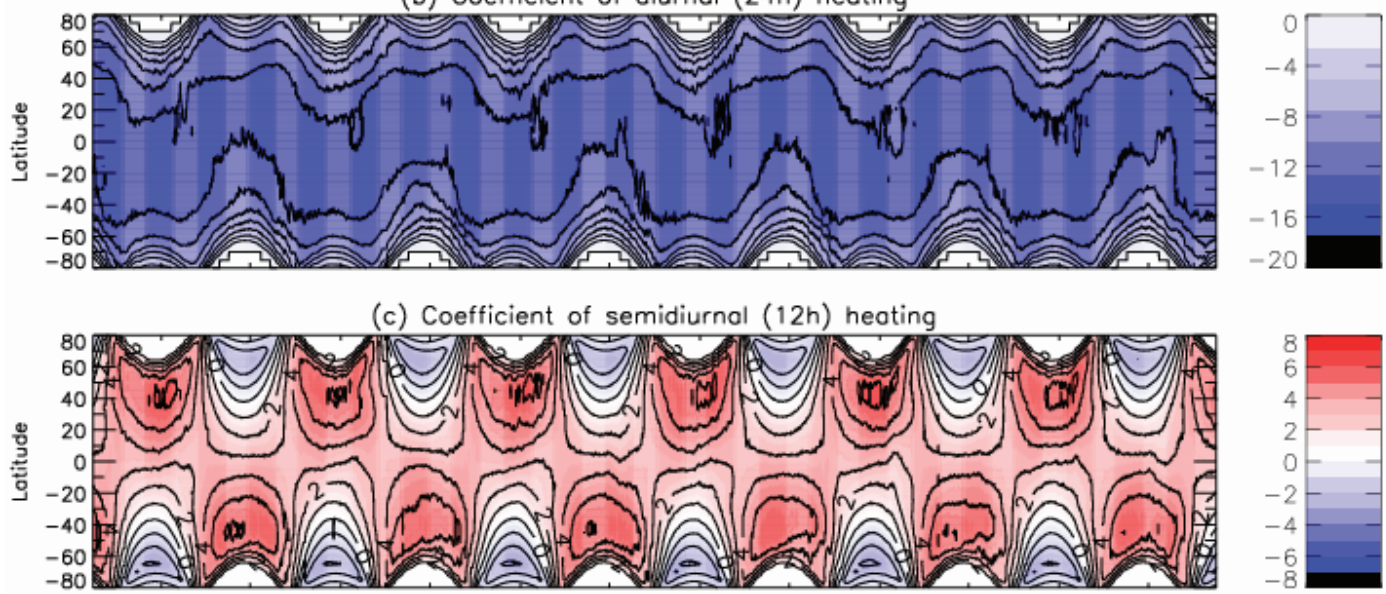

(d) Coefficient of terdiurnal (8h) heoting
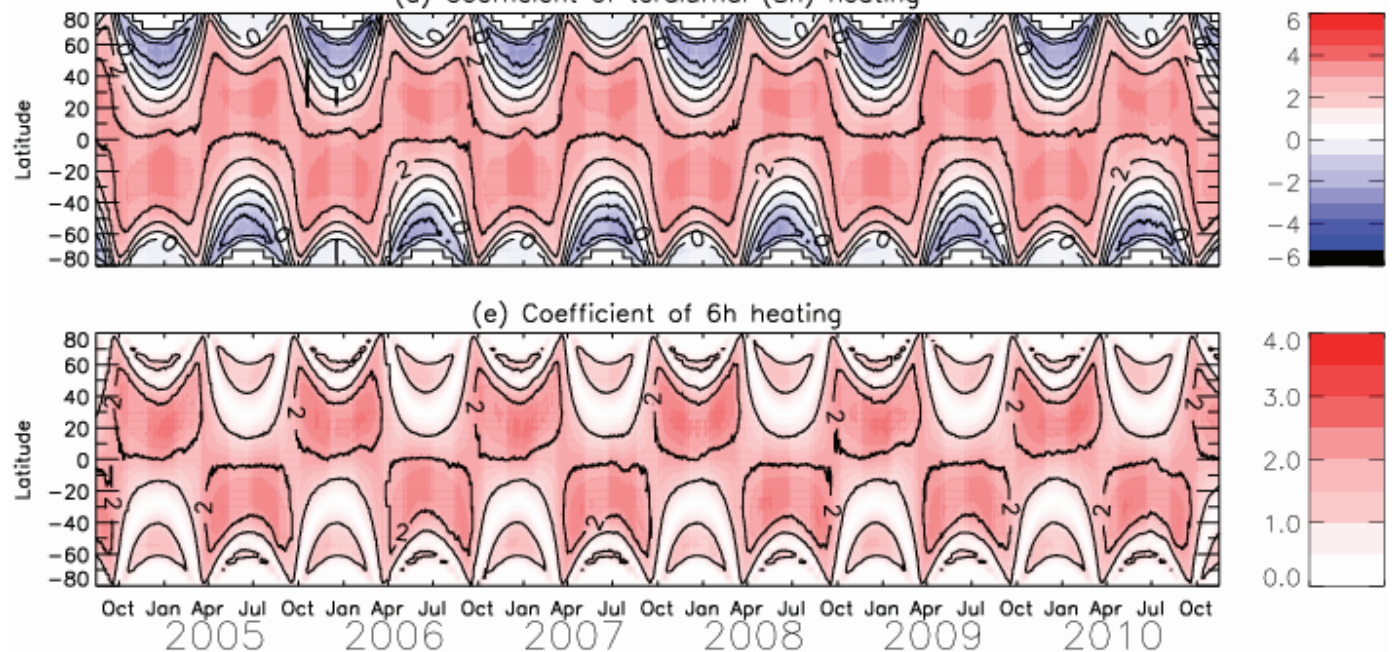

200522006200720082009

Fig. 3. Latitude-time sections of the daily mean (a), diurnal (b), semidiurnal (c), terdiurnal (d), and 6-h (e) components of the ozone heating rate over the period from August 2004 to November 2010 at $50 \mathrm{~km}$. For the tidal components of ozone heating, positive means the phase is at 00:00 LT; negative means the phase is at 12:00 LT for diurnal (b), 06:00 LT for semidiurnal (c), 04:00 LT for terdiurnal (d), and 03:00 LT for 6-h (e).

$25 \mathrm{~km}$ (Fig. 4) shows that weak QBO signatures are apparent in low latitudes: note for example heating maxima in 2006, 2008, and 2010. However, the heating rate is very weak at $25 \mathrm{~km}$ : an order of magnitude less than that at $50 \mathrm{~km}$.

Figures 3 and 4 show that there are slightly differences between the $\mathrm{SH}$ and $\mathrm{NH}$ in the harmonic components in the heating rate, especially for the daily mean component. The heating rate in the high latitudes during Southern Hemisphere
(SH) summer (December and January) is slightly stronger than that in Northern Hemisphere (NH) summer (June and July). This is because of the $6.6 \%$ annual variation of the solar energy input into the Earth's atmosphere due to the annual variation of the Sun-Earth distance. In order to investigate the seasonal asymmetry between DJ (DecemberJanuary) and JJ (June-July), we define the degree of the seasonal asymmetry of a parameter $f$ as follows: 

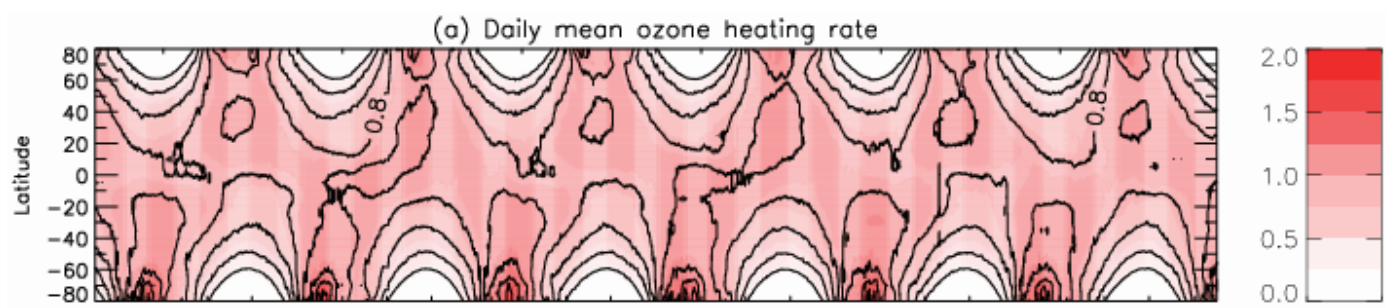

(b) Coefficient of diurnal (24h) heating
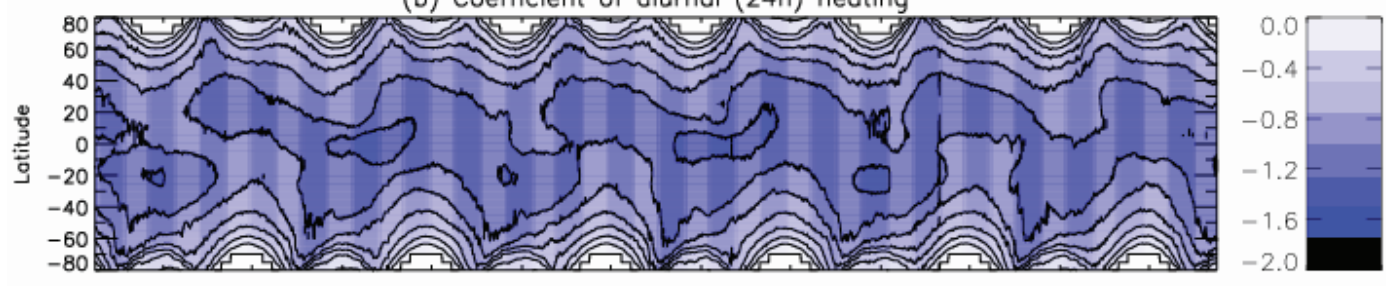

(c) Coefficient of semidiurnal (12h) heoting
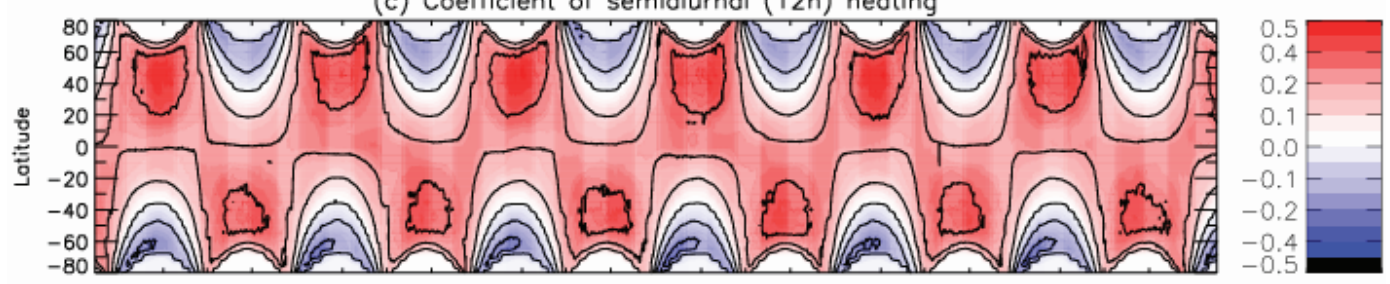

(d) Coefficient of terdiurnal (8h) heoting
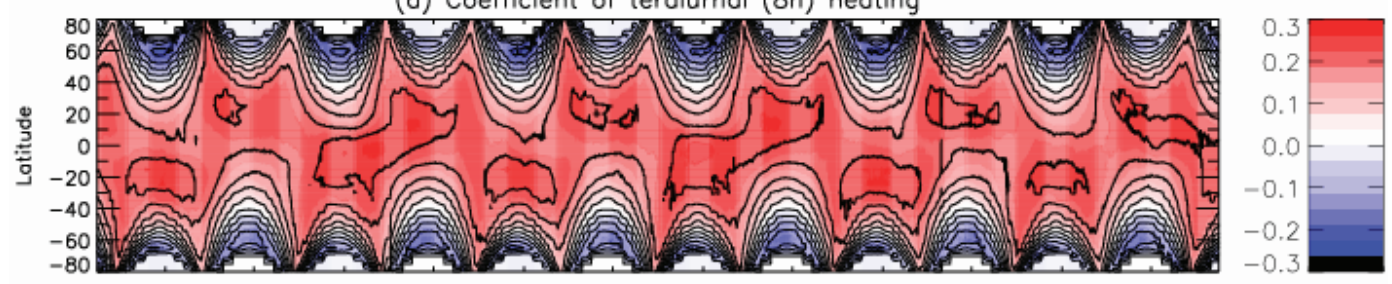

(e) Coefficient of $6 \mathrm{~h}$ heoting
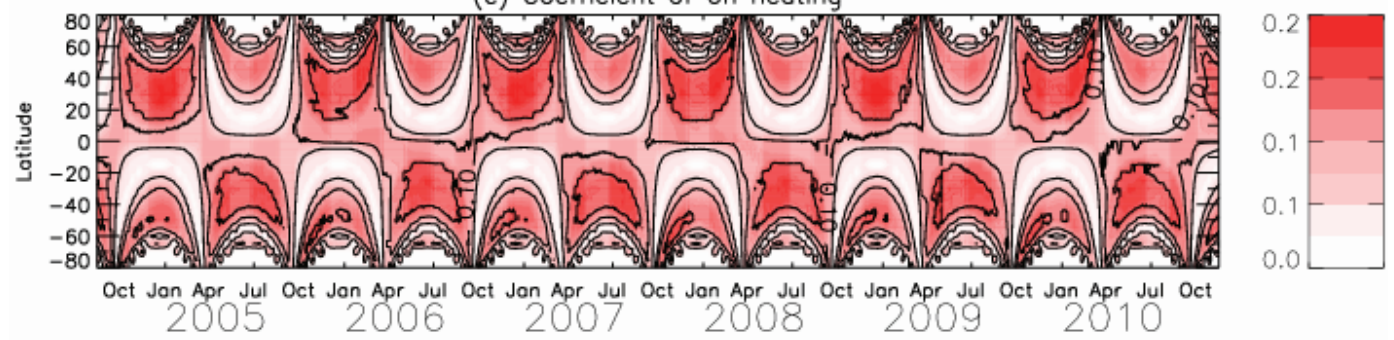

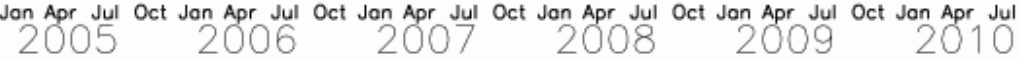

Fig. 4. The same as Fig. 3 but for the altitude of $25 \mathrm{~km}$.

$\eta(z)=2 \frac{\bar{f}_{\mathrm{DJ}}(z)-\bar{f}_{\mathrm{JJ}}(z)}{\left[\bar{f}_{\mathrm{DJ}}(z)+\bar{f}_{\mathrm{JJ}}(z)\right]} \times 100 \%$

where, $\bar{f}$ is the global average of the distribution of $f(z, \theta)$ :

$\bar{f}(z)=\frac{1}{2} \int_{-90^{\circ}}^{90^{\circ}} f(z, \theta) \cos (\theta) d \theta$.

A positive value of $\eta$ indicates that global mean values are higher during $\mathrm{NH}$ winter while a negative values indicates they are higher during SH winter.
Figure 5 shows the degree of the seasonal asymmetry in the ozone density and in the daily mean, diurnal, semidiurnal, 8-h, and 6-h components of the heating rate. The global ozone density is lower during DJ than during JJ (Fig. 5a). Ozone photochemistry depends on the temperature, the ozone production through photolysis of $\mathrm{O}_{2}$, and the loss through many chemical reactions. Both the temperature and the ozone production vary with solar ultraviolet flux; the compounds involved in ozone loss also depend on the solar flux. For example, hydrogen compounds $\left(\mathrm{OH}, \mathrm{HO}_{2}\right.$, etc.) are produced from the oxidation of $\mathrm{H}_{2} \mathrm{O}$ by $\mathrm{O}\left({ }^{1} \mathrm{D}\right)$, which is 

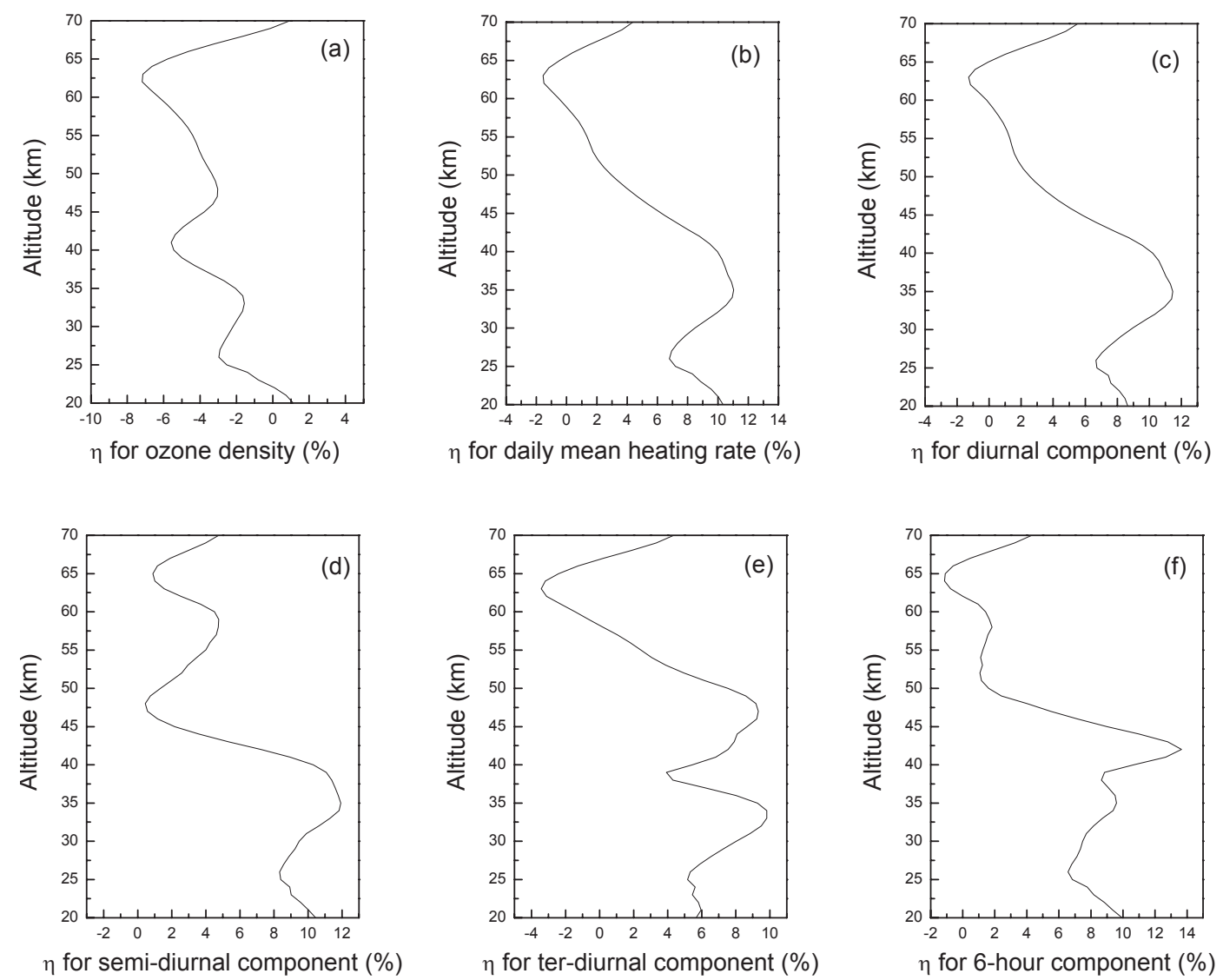

Fig. 5. The degrees of the seasonal asymmetry (\%) between DJ and JJ of the global averages of (a) ozone density; (b) daily mean heating rate; (c) coefficient of the diurnal component; (d) coefficient of the semidiurnal component; (e) coefficient of the 8-h component; (f) coefficient of the 6-h component.

generated during ozone photolysis. Below the stratopause, the photolysis of ozone also depends on absorption of solar radiation in the column above. Figure $5 \mathrm{~b}-\mathrm{f}$ shows that, even though the global ozone is lower, the daily mean and all tidal components of the global averaged heating in the stratosphere are larger during DJ than during JJ. The difference is about $10 \%$. There are two processes that contribute to the annual asymmetry in the heating. The lower global ozone density during DJ (Fig. 5a) contributes to a lower heating rate while the larger solar energy input contributes to a higher heating rate. The heating rate asymmetries shown in Fig. 5 are the result of the competition of the two tendencies. Another process contributes an additional $10 \%$ to the higher heating rate in the stratosphere. Reduced absorption of radiation from the reduced ozone in the lower mesosphere and upper stratosphere leads to deeper penetration of solar radiation into the lower stratosphere; this contributes to the higher heating rate during $\mathrm{JJ}$.

Figure 6 gives the global distributions of the daily mean, diurnal, semidiurnal, terdiurnal, and 6-h components in the ozone heating rate at day 80 in 2005 , representing equinox conditions. All components are almost symmetric between the two hemispheres. The small departures from symmetry reflect differences in the ozone distributions. The maximum of the daily mean heating rate of $10.6 \mathrm{~K} \mathrm{day}^{-1}$ occurs near $48 \mathrm{~km}$ in the tropics. The diurnal component has a peak of $15.6 \mathrm{~K} \mathrm{day}^{-1}$ with a phase of 12:00 LT (the local time of maximum heating rate) in the same region. The magnitude of each increasing frequency is progressively smaller. For the semidiurnal component, the maximum is $5.3 \mathrm{~K} \mathrm{day}^{-1}$ and the phase is at 00:00 LT. For the terdiurnal component, the maximum is $3.3 \mathrm{~K} \mathrm{day}^{-1}$ and the phase is 00:00 LT. For the 6-h component, the maximum is $2.2 \mathrm{~K} \mathrm{day}^{-1}$ with a phase of 03:00 LT. Figure 6 shows that the diurnal and 6-h component in ozone heating rate are negative everywhere, which means that they have minima at 00:00LT. The semidiurnal and terdiurnal components are positive; they reach maximum at 00:00 LT.

Note also in Fig. 6 that the altitude of the maximum heating for the terdiurnal component $(52 \mathrm{~km})$ is higher than for the other components. The shape of the heating variation during a day changes with altitude as the optical depth of the atmosphere changes. Where the optical depth is high, for example in the middle stratosphere, the heating varies with 


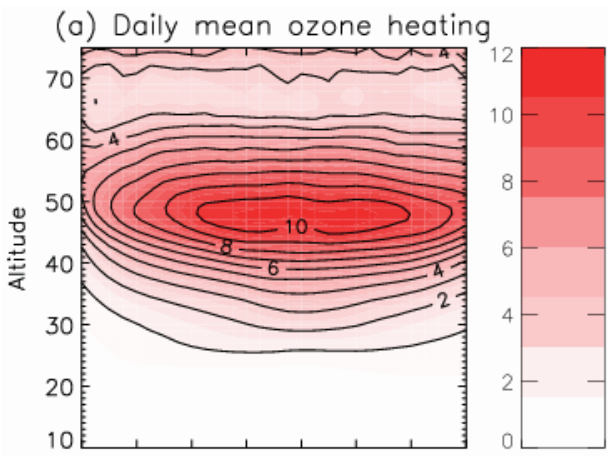

(b) 24 hour component
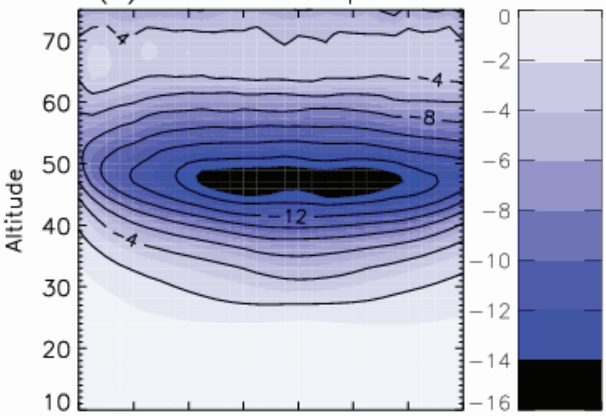

(c) 12 hour component

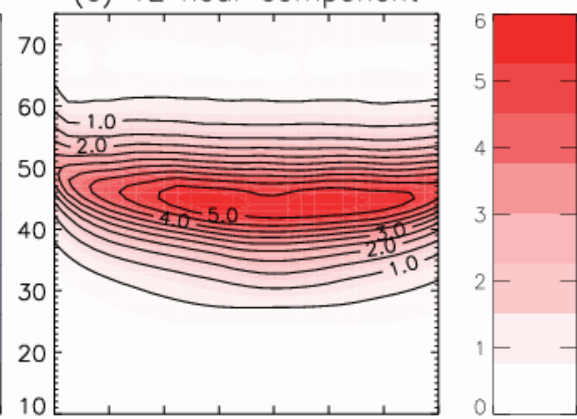

(d) 8 hour component
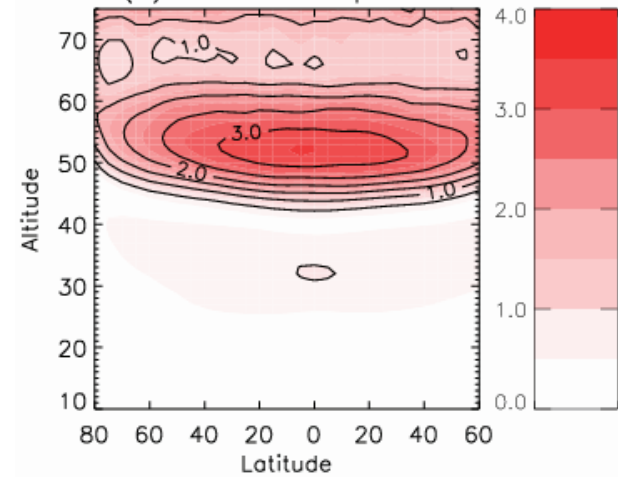

(e) 6 hour component

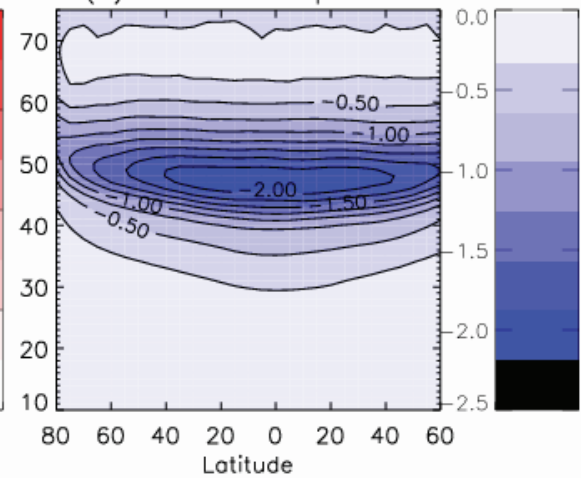

Fig. 6. Latitude-height cross sections of the coefficients of daily mean (a), diurnal (b), semidiurnal (c), terdiurnal (d), and 6-h (e) components of ozone heating rate at day 80 in 2005.

solar zenith angle; the peak heating is at noon and the heating rates drops toward morning and afternoon. For altitudes above the point where the optical depth is unity, the heating becomes more uniform during daylight hours and, equivalently, more box-like over a $24 \mathrm{~h}$ period. This gives rise to the variation in the frequency decomposition with altitude. The altitude variations are also affected by the solar zenith angle changes with latitude and time of year.

Figure 7 gives latitude-height distributions of the daily mean, diurnal, semidiurnal, terdiurnal, and 6-h components in ozone heating rate at day 170 in 2005 , representing solstice conditions. The situation during solstice is much more complex than that during equinox. To help make sense of the variations, we present the latitude and local time variations of each component at $50 \mathrm{~km}$ in Fig. 8.
Figure 8a shows that the maximum ozone heating rate at the altitude of $50 \mathrm{~km}$ at the June solstice is $25.2 \mathrm{~K} \mathrm{day}^{-1}$ at noon near the latitude of $25^{\circ}$ in the summer hemisphere. However, the maximum of the daily mean heating rate at $50 \mathrm{~km}\left(15.3 \mathrm{~K} \mathrm{day}^{-1}\right.$, see Fig. 7a) occurs in the summer polar region at day 170 . The polar maximum in the daily mean heating reflects the long (up to $24 \mathrm{~h}$ ) duration of daylight in the polar summer. For the diurnal component (Figs. $7 \mathrm{~b}$ and 8c), the maximum (negative) heating occurs at 12:00 LT at all latitudes. The heating rate peak occurs at $47 \mathrm{~km}$ at $25^{\circ}$ in the summer hemisphere. The semidiurnal component (Figs. 7c and $8 \mathrm{~d}$ ) has two peaks. The larger has a 00:00 LT maximum and occurs at $47 \mathrm{~km}$ at $45^{\circ}$ in the winter hemisphere. The smaller has a maximum at 06:00 LT at $56 \mathrm{~km}$ near $60^{\circ}$ in the summer hemisphere. The pattern continues. The terdiurnal tidal heating has three peaks and the 6-h tide has four 


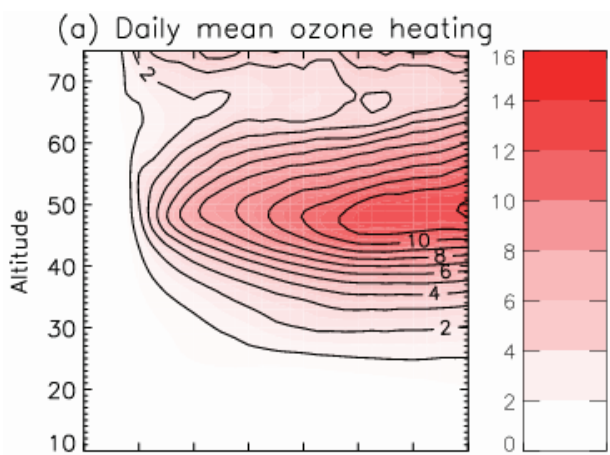

(b) 24 hour component

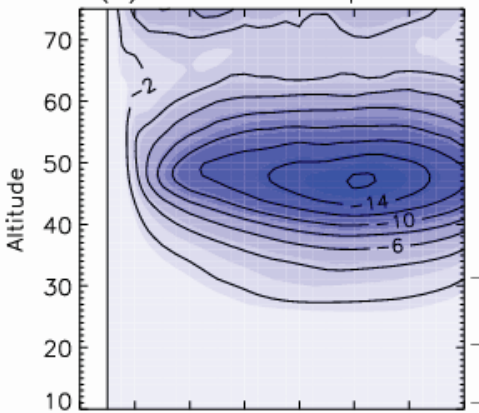

(d) 8 hour component
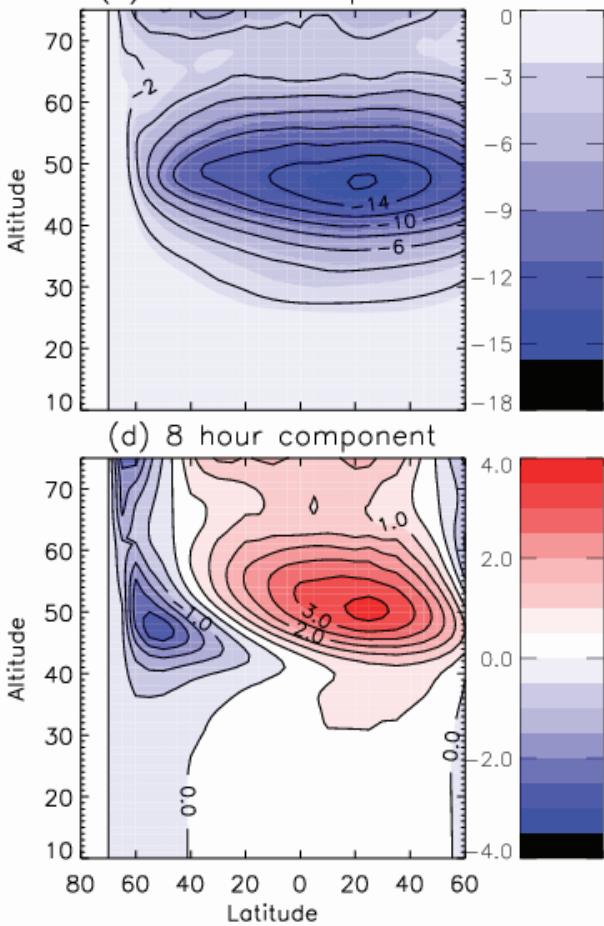

(c) 12 hour component
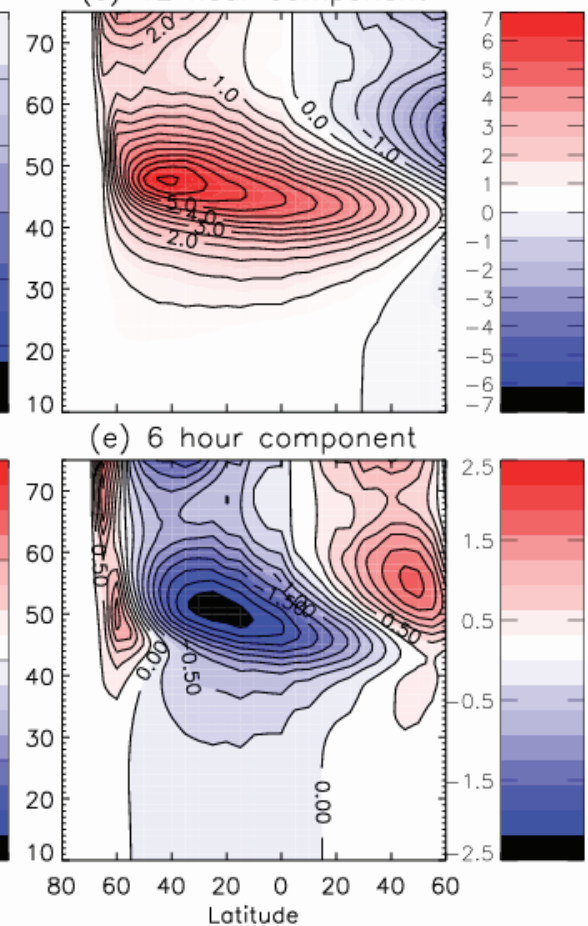

Fig. 7. The same as Fig. 6, but for day 170 in 2005.

peaks. In all cases, the phase alternates between adjacent peaks. The magnitude of the heating rate is progressively smaller for each component.

In the next three sections, we will discuss the temporal variations of the semidiurnal, terdiurnal and $6 \mathrm{~h}$ components in the ozone heating rate for comparison with those of the diurnal tide presented in Xu et al. (2010). Owing to very weak QBO in the harmonic components in ozone heating rate, we focus on the annual (AO) and semi-annual (SAO) oscillations.

\section{The seasonal variations in the semidiurnal component of ozone heating}

\subsection{Seasonal variations of the total semidiurnal compo- nent of heating rate}

Figure 9 gives the averaged value and the amplitudes and phases of the seasonal oscillations of the semidiurnal component in the heating rate as a function of latitude and altitude, calculated by Eq. (5). The maximum of the averaged semidiurnal component in heating rate is about $5.4 \mathrm{~K} \mathrm{day}^{-1}$ near the altitude of $44 \mathrm{~km}$ at the equator. The positive value indicates maxima at 00:00 LT and 12:00 LT. There are very small negative values in the high latitude in the region of 50$60 \mathrm{~km}$; in these regions, the strongest semidiurnal heating occurs at 06:00 LT and 18:00 LT. The peak SAO amplitude of $2.5 \mathrm{~K} \mathrm{day}^{-1}$ occurs in high latitudes (centered around $65^{\circ}$ ) 


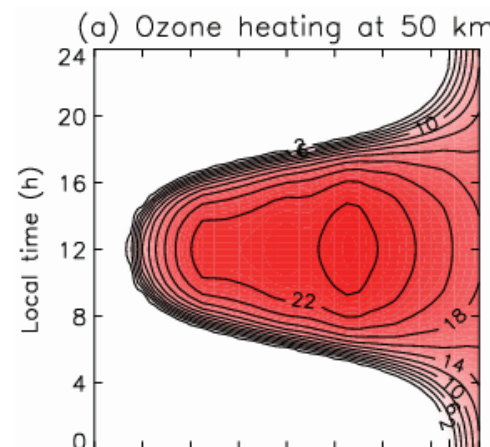

(c) 24 hour component

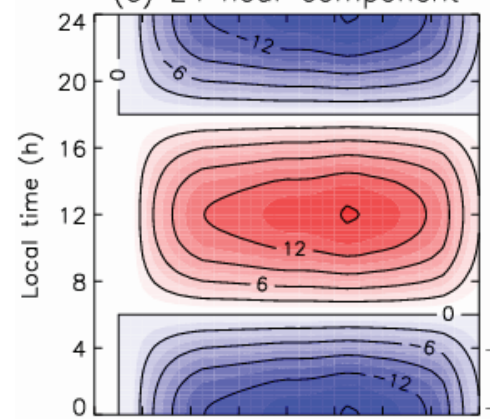

(e) 8 hour component

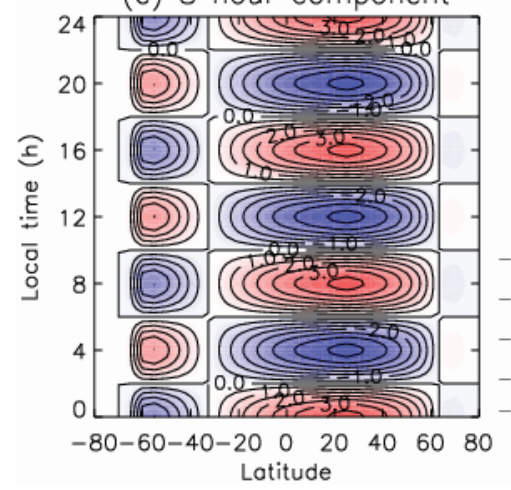

(b) Daily average component
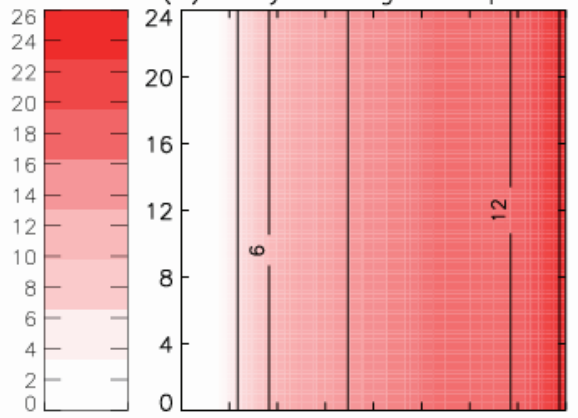

(d) 12 hour component
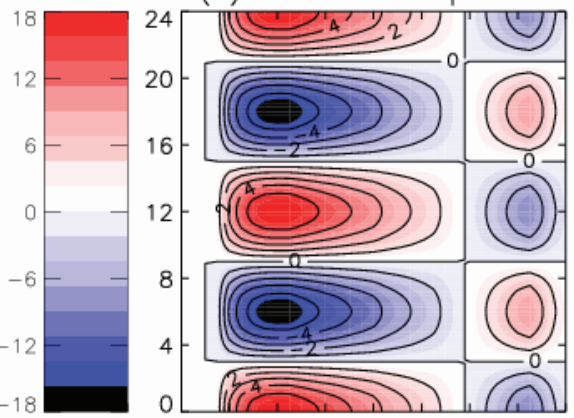

(f) 6 hour component
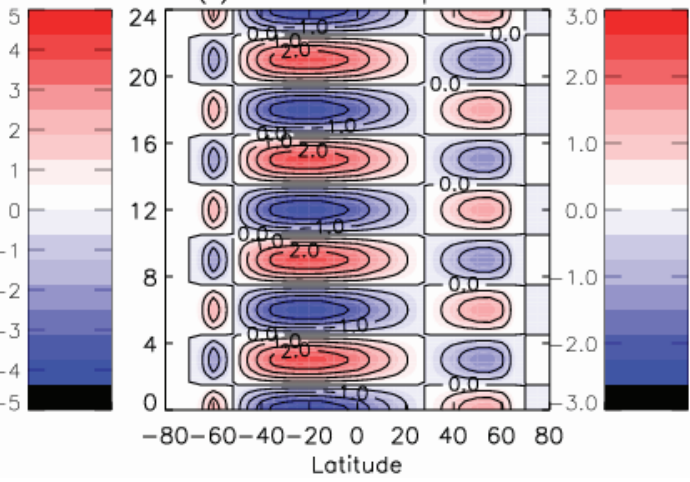

Fig. 8. Local time-latitude cross sections of the total ozone heating rate (a) and daily mean (b), diurnal (c), semidiurnal (d), terdiurnal (e), and 6-h (f) components of heating at the altitude of $50 \mathrm{~km}$ on day 170 in 2005.

near $48 \mathrm{~km}$ (see Fig. 9b), and the phase is near the equinox (Fig. 9c) in both hemispheres. The maximum of the amplitude of $\mathrm{AO}$ is $3.8 \mathrm{~K} \mathrm{day}^{-1}$ at about $53 \mathrm{~km}$ near the latitude of $60^{\circ}$ in both hemispheres (see Fig. 9d). The phase in Fig. 9e shows that the annual oscillation reaches maximum near the winter solstice, in contrast to the diurnal component, which is maximum at the summer solstice (see Fig. $7 \mathrm{f}$ in $\mathrm{Xu}$ et al., 2010).

The calculations show that the $\mathrm{QBO}$ in the semidiurnal tide is very weak $\left(0.1 \mathrm{Kday}^{-1}\right)$; this is not shown.

The analysis of the semidiurnal temperature tide using TIMED/SABER data shows that the amplitude below $90 \mathrm{~km}$ is larger in the middle latitudes of the winter hemisphere than in the summer hemisphere (Pancheva et al., 2009). The winds observed by HRDI (the high resolution Doppler imager) on UARS (the Upper Atmosphere Research Satellite) satellite indicated that the seasonal variation of the semidiurnal tide prevail at middle and high latitude and there are larger in winter than in summer (Burrage et al., 1995). Radar observations of horizontal winds at Esrange $\left(68^{\circ} \mathrm{N}, 21^{\circ} \mathrm{E}\right)$ indicate that semidiurnal tidal wave is largest during midwinter (Fig. 2 in Smith et al., 2004). Many meteor radar and lidar observations also revealed the winter maximum of the semidiurnal tide in the MLT region (e.g. Mitchell et al., 2002; Manson et al., 2004; Yuan et al., 2008).

\subsection{Seasonal variations of the semidiurnal Hough modes in the heating rate}

Figure 10 shows vertical profiles of the first four symmetric and asymmetric semidiurnal Hough functions for equinox/March and solstice/June conditions. At equinox, the 

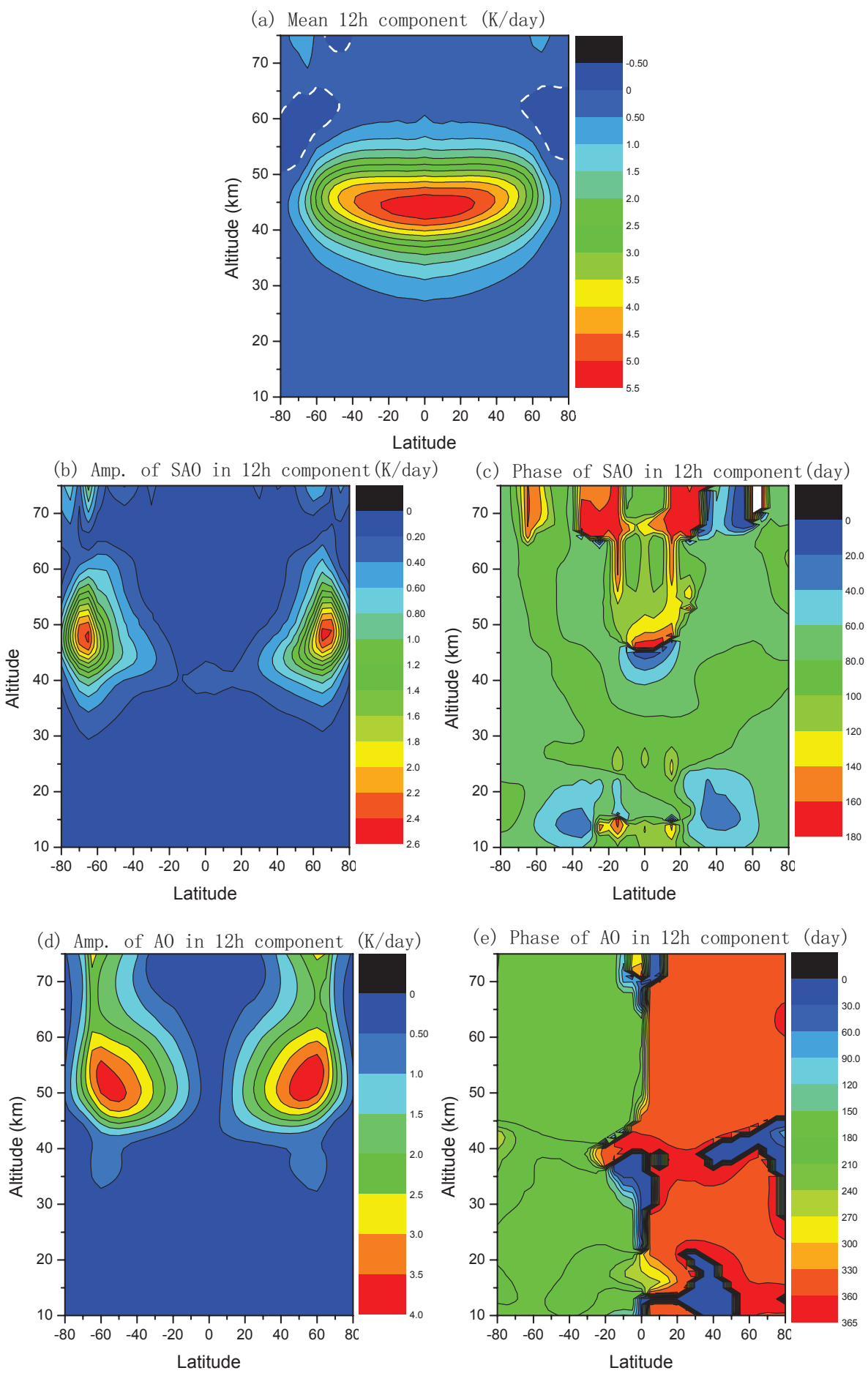

Fig. 9. The annual mean semidiurnal component in ozone heating rate over the period from August 2004 to November 2010 (a); the amplitudes (b), (d) and the phases (c), (e) of the SAO and AO variations in the semidiurnal component in ozone heating rate. The phase labels give the day of maximum heating. The white dashed line shows the boundary between positive and negative.

semidiurnal heating projects almost entirely onto the symmetric Hough modes. The $(2,2)$ mode is the strongest; it has a peak of $6 \mathrm{~K} \mathrm{day}^{-1}$. The intensities of the high-order modes decrease monotonically with increase of order $n$. The magnitudes of the asymmetric modes are small and can be neglected at equinoxes. During the solstice, the heating rate in the symmetric modes is smaller than it is at equinox. The relative decrease is more prominent for higher-order than 

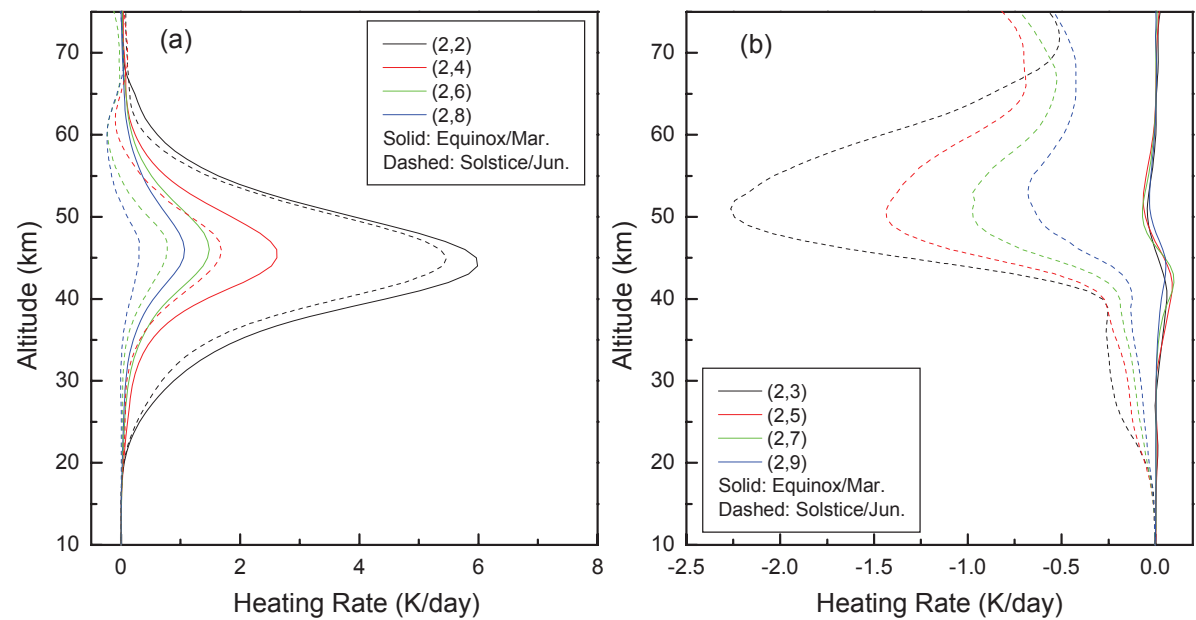

Fig. 10. The multi-year averaged vertical profiles of the symmetric (a) and asymmetric (b) semidiurnal Hough functions for equinox/March (solid line) and solstice/June (dashed line).
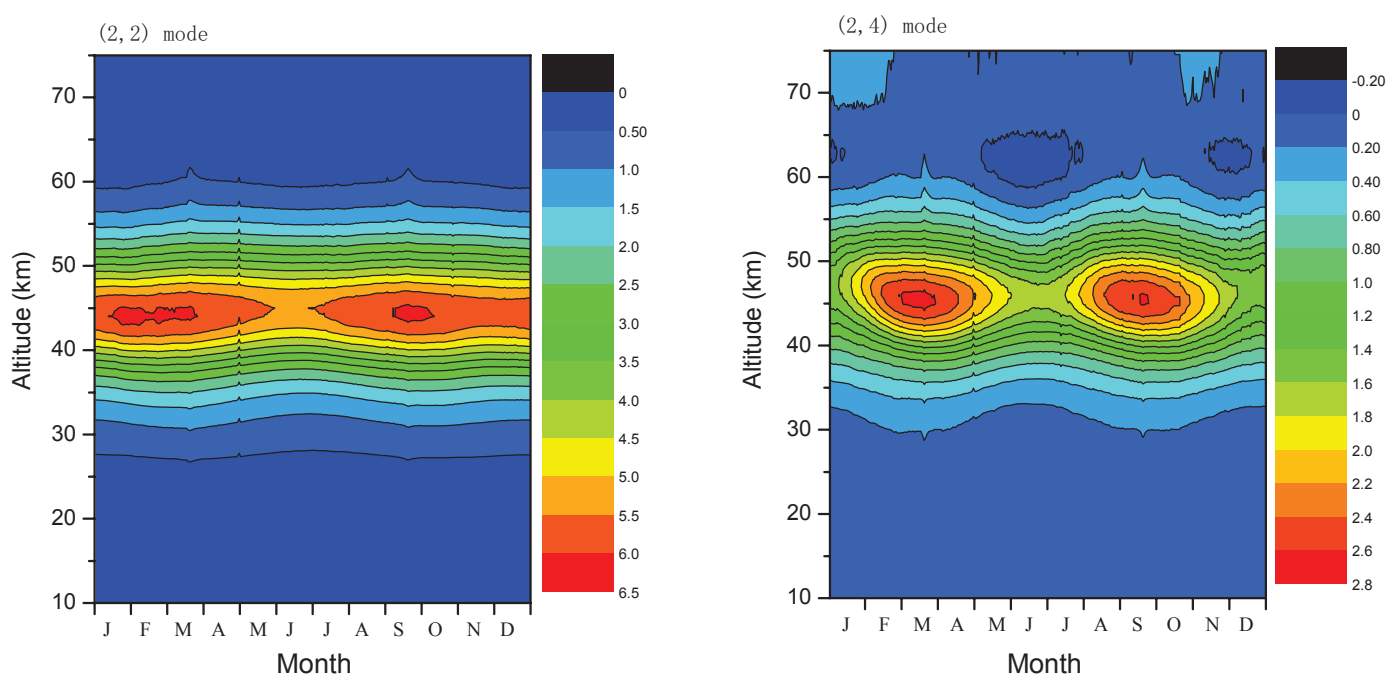

Fig. 11. Time-altitude cross-sections of the monthly averaged amplitudes of the semidiurnal Hough modes $(2,2)$ and $(2,4)$.

lower-order modes. Figure 11 shows multi-year averaged altitude-month cross sections of the magnitudes of the symmetric semidiurnal Hough modes $(2,2)$ and $(2,4)$. The peak heating rates of these modes are $9 \%$ and $36 \%$ smaller at solstice relative to equinox. The decreases of the higher-order modes are even more pronounced. Figure 10b shows that, during the solstice, the magnitudes of the asymmetric modes become strong while the symmetric modes are weak.

Figure 12 summarizes the seasonal variations of the Hough modes of the semidiurnal heating rate calculated by Eq. (5). The magnitudes of the Hough modes decrease rapidly with order $n$. Modes that are large during both equinox and solstice, e.g. $(2,2)$ and $(2,4)$, dominate the annual mean semidiurnal forcing. The symmetric modes all have largest magnitudes during equinoxes and have SAO variations. This is apparent from the phases (around day 80) in Fig. 12. The asymmetric modes are very small at equinoxes and largest near the solstices; their variation is dominated by an annual cycle. The one exception is a weak $\mathrm{AO}$ in the symmetric $(2,2)$ mode. This annual variation in the symmetric part of the heating results from variations of the solar radiation due to the annual cycle in Sun-Earth distance and from the seasonal asymmetry of ozone (Fig. 5). 

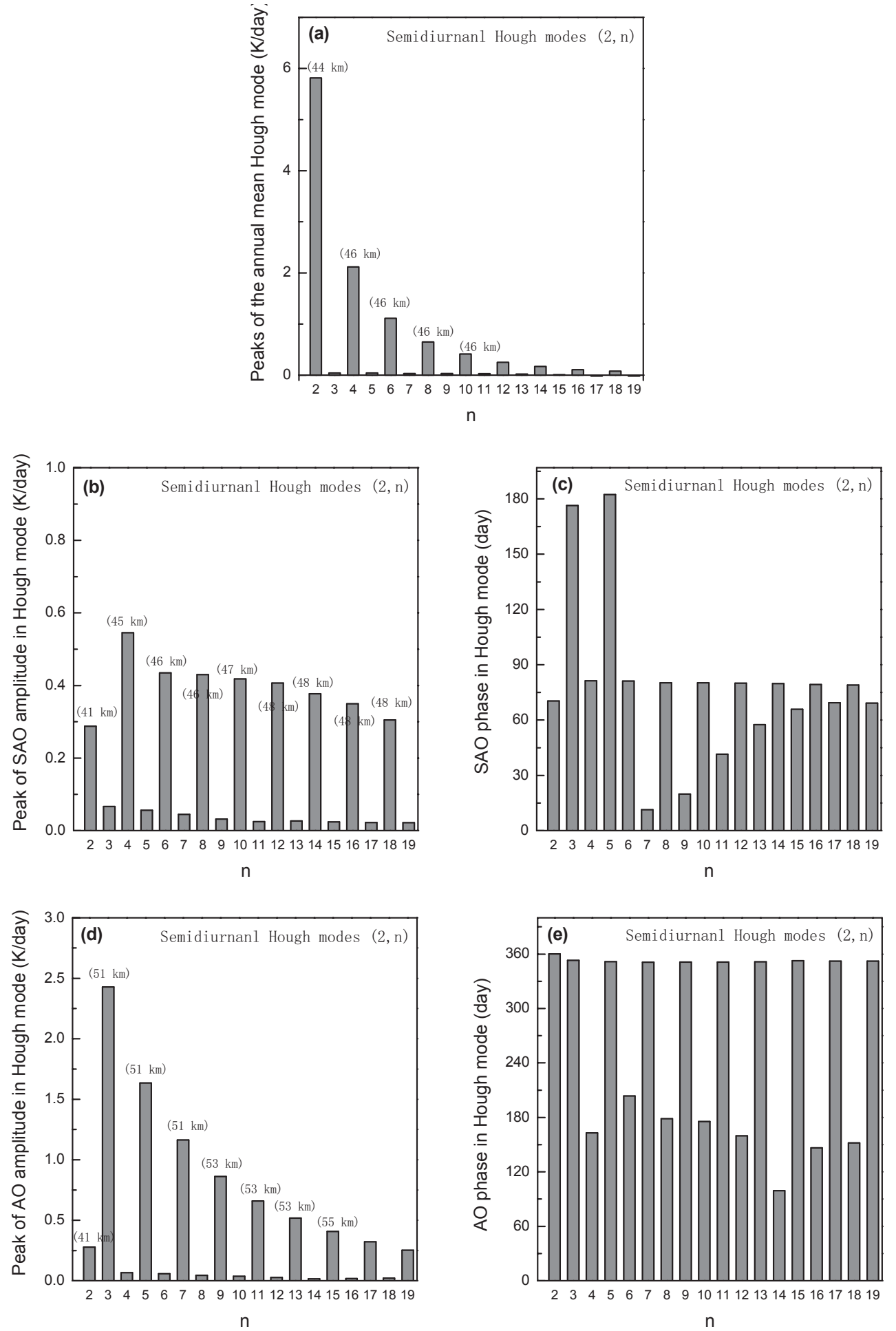

$\mathrm{N}=2$ for solar-earth distance variation.

Fig. 12. (a) The coefficients of the annual mean semidiurnal heating Hough modes $(2, n)$; (b) and (c) the amplitudes and phases of the SAO in the semidiurnal heating Hough modes; (d) and (e) the amplitudes and phases of the AO in the semidiurnal heating Hough modes. The altitudes of the Hough mode peaks are given in brackets. 
(a) Mean $8 \mathrm{~h}$ component (K/day)

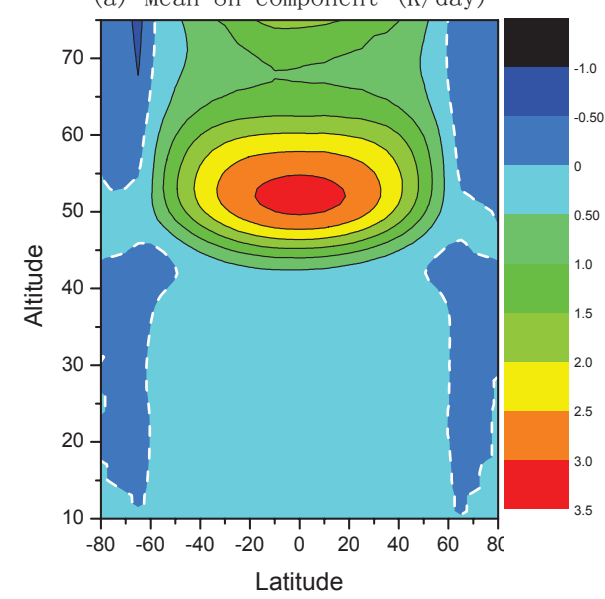

(b) Amp. of SA0 in $8 \mathrm{~h}$ component (K/day)

(c) Phase of SA0 in $8 \mathrm{~h}$ component (day)
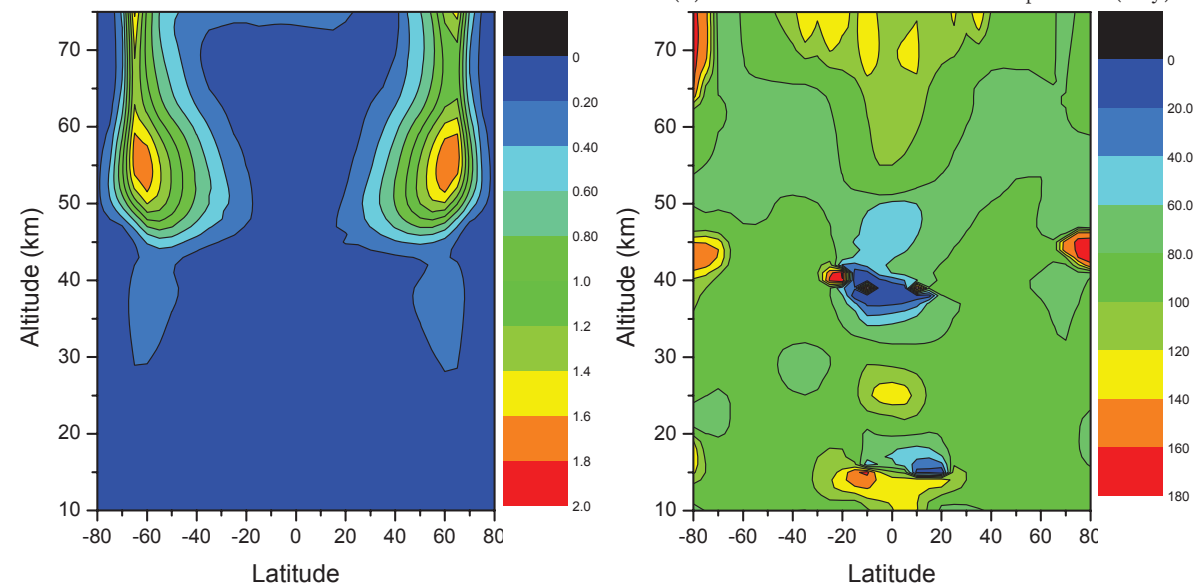

(d) Amp. of $\mathrm{A} 0$ in $8 \mathrm{~h}$ component (K/day)

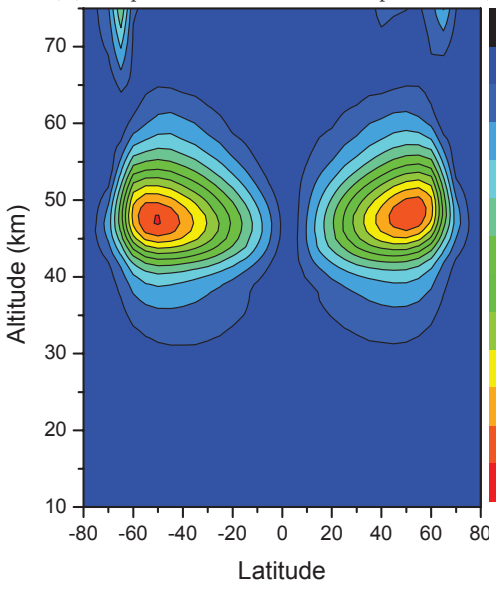

(e) Phase of $\mathrm{A} 0$ in $8 \mathrm{~h}$ component (day)

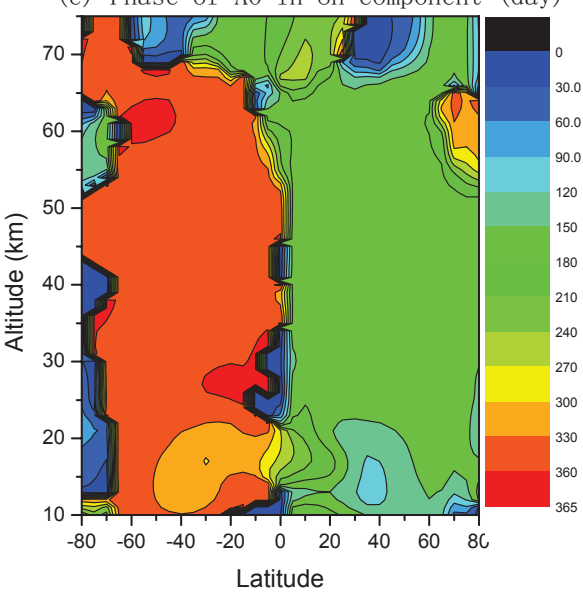

Fig. 13. The same as Fig. 9, but for terdiurnal component. 

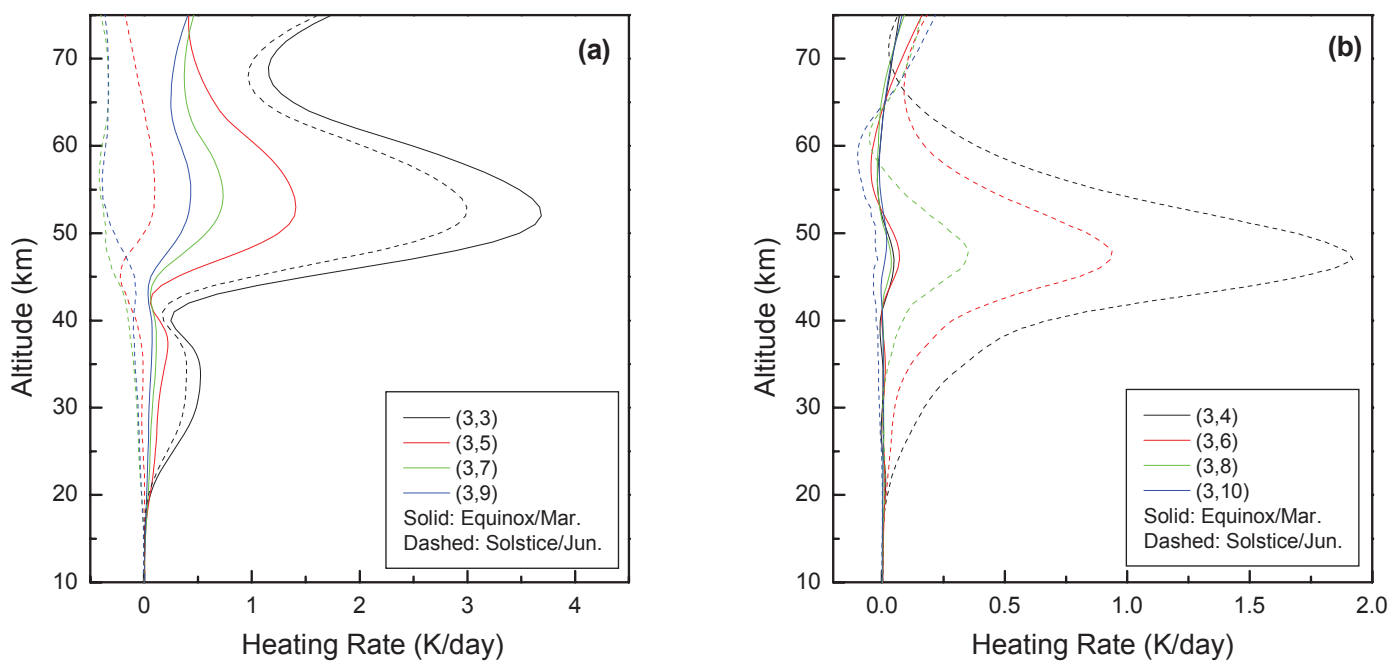

Fig. 14. Multi-year averaged vertical profiles of the symmetric (a) and asymmetric (b) terdiurnal Hough functions for equinox/March (solid line) and solstice/June (dashed line).

\section{The seasonal variations in the terdiurnal component of the heating rate}

\subsection{Seasonal variations of the total terdiurnal compo- nent of heating rate}

The averaged value and the amplitudes and phases of the seasonal oscillations of the terdiurnal component in the ozone heating rate as a function of latitude and altitude are given in Fig. 13. The maximum of the averaged terdiurnal component in heating rate is about $3.2 \mathrm{~K} \mathrm{day}^{-1}$ near the altitude of $52 \mathrm{~km}$ at the equator. Its phase over most of the globe is 00:00 LT (positive indicates a midnight maximum) although there are very small negative values (about $0.5 \mathrm{~K} \mathrm{day}^{-1}$ ) in high latitudes. Figure $13 \mathrm{~b}$ shows that the peak SAO amplitude occurs around $60^{\circ}$ near $55 \mathrm{~km}$, and the phase is near the equinox (see Fig. 13c). Two AO amplitude maxima occur at about $47 \mathrm{~km}$ near $50^{\circ}$ in the two hemispheres (Fig. 13d). The phase in Fig. 13e shows that the annual oscillation reaches maximum near the summer solstice, opposite to that of the semidiurnal component (see Fig. 9e). The maximum amplitude of the QBO in terdiurnal forcing (not shown) is very weak (only $0.07 \mathrm{~K} \mathrm{day}^{-1}$ ).

\subsection{Seasonal variations of the terdiurnal Hough modes in the heating rate}

Figure 14 gives vertical profiles of the first four symmetric and asymmetric terdiurnal Hough functions for equinox/March and solstice/June. During the equinox, the terdiurnal heating is distributed into the first several symmetric Hough modes. The $(3,3)$ mode is the strongest; its peak amplitude is $3.7 \mathrm{~K} \mathrm{day}^{-1}$ at $53 \mathrm{~km}$. The magnitudes of the higher-order modes decrease with increasing order $n$. For instance, the magnitude of $(3,5)$ mode is $1.4 \mathrm{~K} \mathrm{day}^{-1}$ at $53 \mathrm{~km}$, which is smaller by more than a factor of two than the $(3,3)$ mode. During the solstice, the heating rate in the symmetric modes is much smaller than during equinox. The relative decrease is more pronounced for higher-order than lower-order mode. The SAO for the symmetric Hough modes is very strong, especially for the higher-order Hough modes. The asymmetric modes are small during equinox and can be neglected. Figure $14 \mathrm{~b}$ shows that the magnitudes of asymmetric modes become strong during the solstice.

Figure 15 summarizes the seasonal variations of the Hough modes of the terdiurnal heating rate. SAO variations (evident by equinox maxima) are mainly seen in the first 5 symmetric mode and the phases are all near equinox. The first of these modes $(3,3)$ also makes a contribution to the annual mean (evident by large equinox and solstice magnitudes). The relative importance of the SAO is larger in higher-order terdiurnal symmetric Hough modes. The annual variations are evident by the higher solstice magnitudes in the first four asymmetric modes: $(3,4),(3,6),(3,8)$, and $(3,10)$.

Smith and Ortland (2001) and Akmaev (2001) simulated the global structure of the terdiurnal tide. They pointed out that the first symmetric mode $(3,3)$ is evanescent and cannot propagate vertically; other modes are able to propagate.

\section{The seasonal variations in 6-h component of the heating rate}

\subsection{Seasonal variations of the total 6-h component of heating rate}

Figure 16 shows the latitude-height sections of the annual averaged value and the amplitudes and phases of the seasonal oscillations of the 6-h component in the ozone heating rate. 

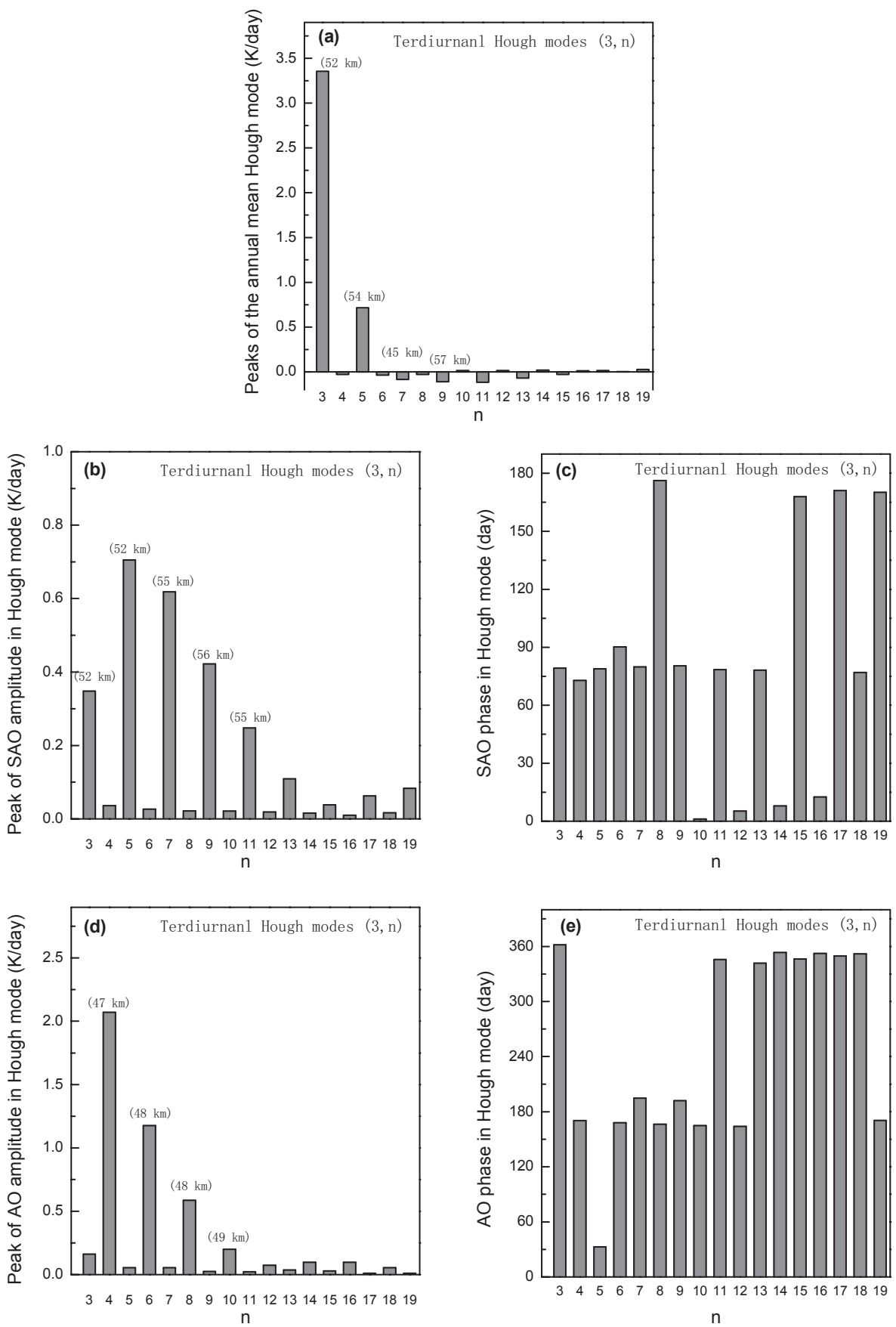

Fig. 15. The same as Fig. 12, but for terdiurnal Hough modes.

The maximum of the averaged 6-h component in heating rate is about $2.2 \mathrm{~K} \mathrm{day}^{-1}$ near the altitude of $47 \mathrm{~km}$ at the equator. The phase at the equator (negative) indicates a midnight minimum. There are small regions with very small positive values (about $0.2 \mathrm{~K} \mathrm{day}^{-1}$ ) in the high latitudes. Figure $16 \mathrm{~b}$ and $\mathrm{c}$ shows that the peak SAO amplitude of $1.5 \mathrm{~K} \mathrm{day}^{-1} \mathrm{oc}-$ curs around $60^{\circ}$ near $50 \mathrm{~km}$, and the phase is near the solstice (day 170). To interpret this, take into account the negative value of the annual averaged amplitude; this means that the 6-h heating is most strongly forced near the equinoxes. The maximum of the amplitude of $\mathrm{AO}$ is $1.9 \mathrm{~K} \mathrm{day}^{-1}$ at about $55 \mathrm{~km}$ near $45^{\circ}$ in both hemispheres (see Fig. 16d). The phase in Fig. 16e shows that the annual 6-h heating maximum occurs near the summer solstice. The 6-h component is similar to the 12-h component in that the maximum forcing occurs in the winter hemisphere. As in the other tidal heating 

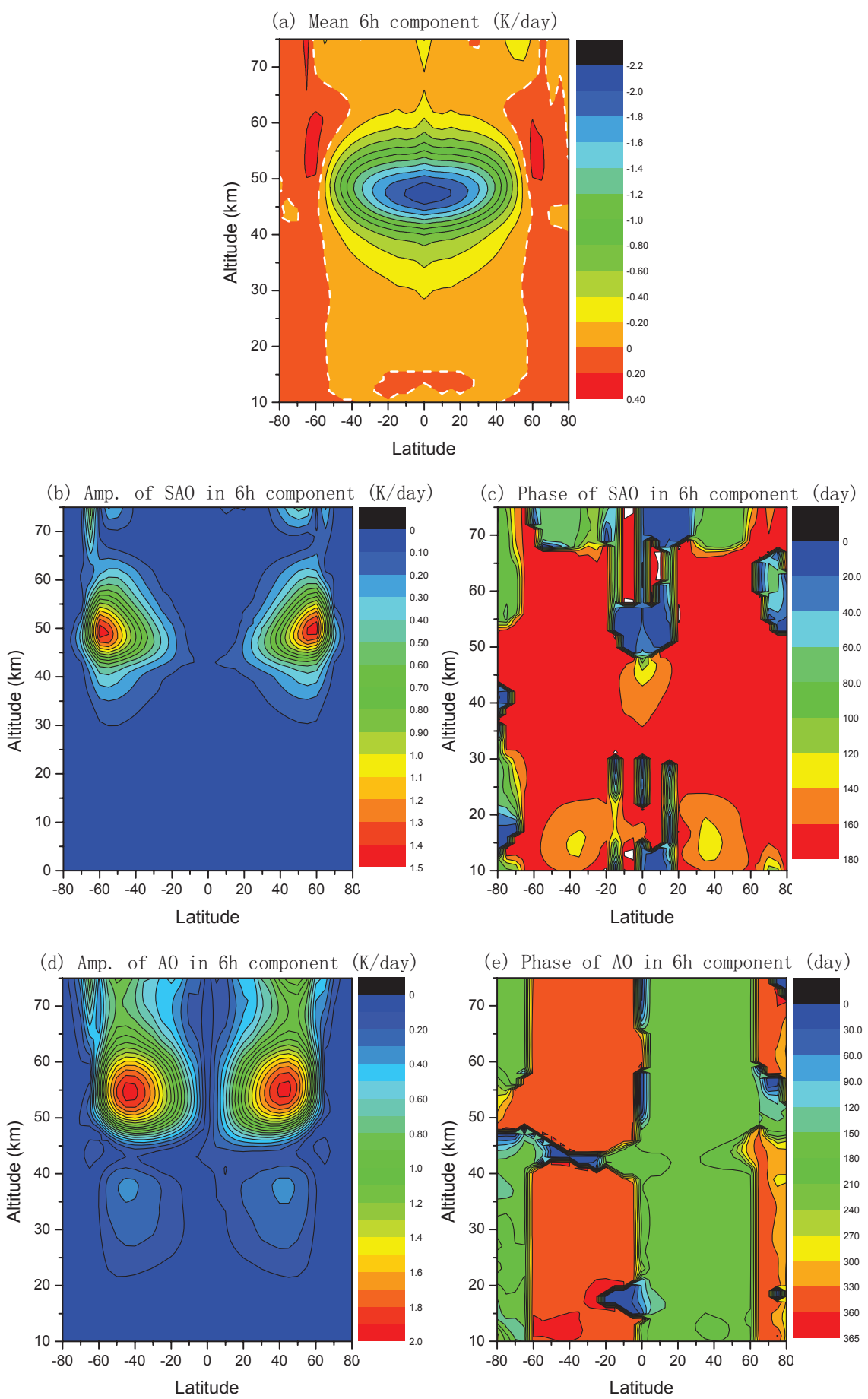

Fig. 16. The same as Fig. 9, but for 6-h component.

terms, the maximum amplitude of the QBO in the 6-h heating is very weak (only $0.05 \mathrm{~K} \mathrm{day}^{-1}$ ) and is not shown.

\subsection{Seasonal variations of the 6-h Hough modes in the heating rate}

Figure 17 gives vertical profiles of the first four symmetric and asymmetric 6-h Hough functions for equinox/March and solstice/June. Figure 17a shows that, during the equinox, the 6-h heating projects most strongly onto the first three 

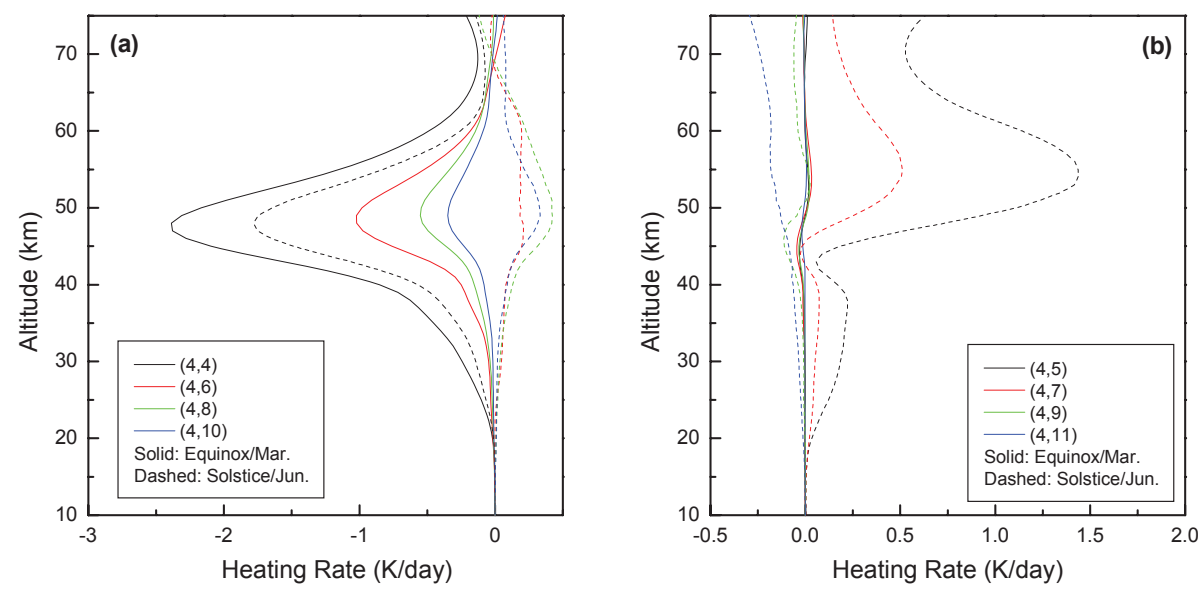

Fig. 17. The multi-year averaged vertical profiles of the symmetric (a) and asymmetric (b) 6-h Hough functions for equinox/March (solid line) and solstice/June (dashed line).

symmetric Hough modes; the $(4,4)$ mode is the strongest. The magnitudes of the high-order modes decrease with increasing of order $n$. The heating rate of the symmetric modes is much smaller during the solstice than equinox. The relative decrease is more prominent for higher-order modes; this indicates that there are very strong SAO for the symmetric higher order Hough modes. The asymmetric modes can be neglected during the equinox but they become strong during the solstice seasons.

Figure 18 summarizes the seasonal variations of the Hough modes of the 6-h heating rate. This is similar to the semidiurnal and terdiurnal heating in the following aspects: the heating is largest in the first few modes; the symmetric modes primarily contribute to the annual average and the $\mathrm{SAO}$ while the asymmetric modes primarily contribute to the AO.

\section{Summary}

In this paper, we use AURA/MLS observed ozone data from August 2004 to November 2010 and the Strobel/Zhu parameterized model to calculate the ozone heating rate in the stratosphere and lower mesosphere. The heating is then decomposed into the daily mean, diurnal, semidiurnal, terdiurnal, and 6-h harmonic components. We also decompose each of these into its Hough modes. Seasonal variations and global distributions of the harmonic components and the leading Hough modes are presented.

The calculations show that the maximum ozone heating of all components occurs near the stratopause. During the equinoxes, all components are symmetric between the two hemispheres. During the solstice seasons, the diurnal and terdiurnal components have stronger heating in the summer hemisphere while the semidiurnal and 6-h components have stronger heating in the winter hemisphere. All components have strong SAO and AO in the middle and high latitudes.

The ozone density distribution has an obvious seasonal asymmetry between DJ (December-January) and JJ (JuneJuly). The observed seasonal asymmetry in the ozone density distribution, along with the $6.6 \%$ annual variation of the solar energy input into the Earth's atmosphere due to the annual variation of the Sun-Earth distance, leads to seasonal asymmetries in the daily mean and tidal components of the ozone heating rate between DJ and JJ. The global averaged heating rate in the stratosphere during SH summer is slightly stronger than that in NH summer. The difference is about $10 \%$ in the stratosphere for daily mean and tidal components.

In the vicinity of the stratopause, where the heating rates reach maximum, the variations due to the $\mathrm{QBO}$ are negligibly small in all components. In the lower stratosphere, there are weak QBO signatures in low latitude but the overall heating rate is very weak there.

Detailed analysis of the diurnal (24-h) component of the heating was presented by Xu et al. (2010) and will not be repeated here. The results for the semidiurnal, terdiurnal and 6-h harmonic components are as follows:

\section{Semidiurnal component:}

During the equinox season, the sign is positive (midnight and noon maxima), and symmetric between the two hemispheres.

During the solstice season, the heating rate in the winter hemisphere is stronger than in the summer hemisphere; the location of the largest heating rate is near $40^{\circ}$ at the winter hemisphere stratopause; and the heating in two hemispheres is out of phase.

The semidiurnal component mainly projects onto the low-order Hough modes. The SAO variability is relatively more important for the higher-order semidiurnal symmetric Hough modes than for the lower-order 

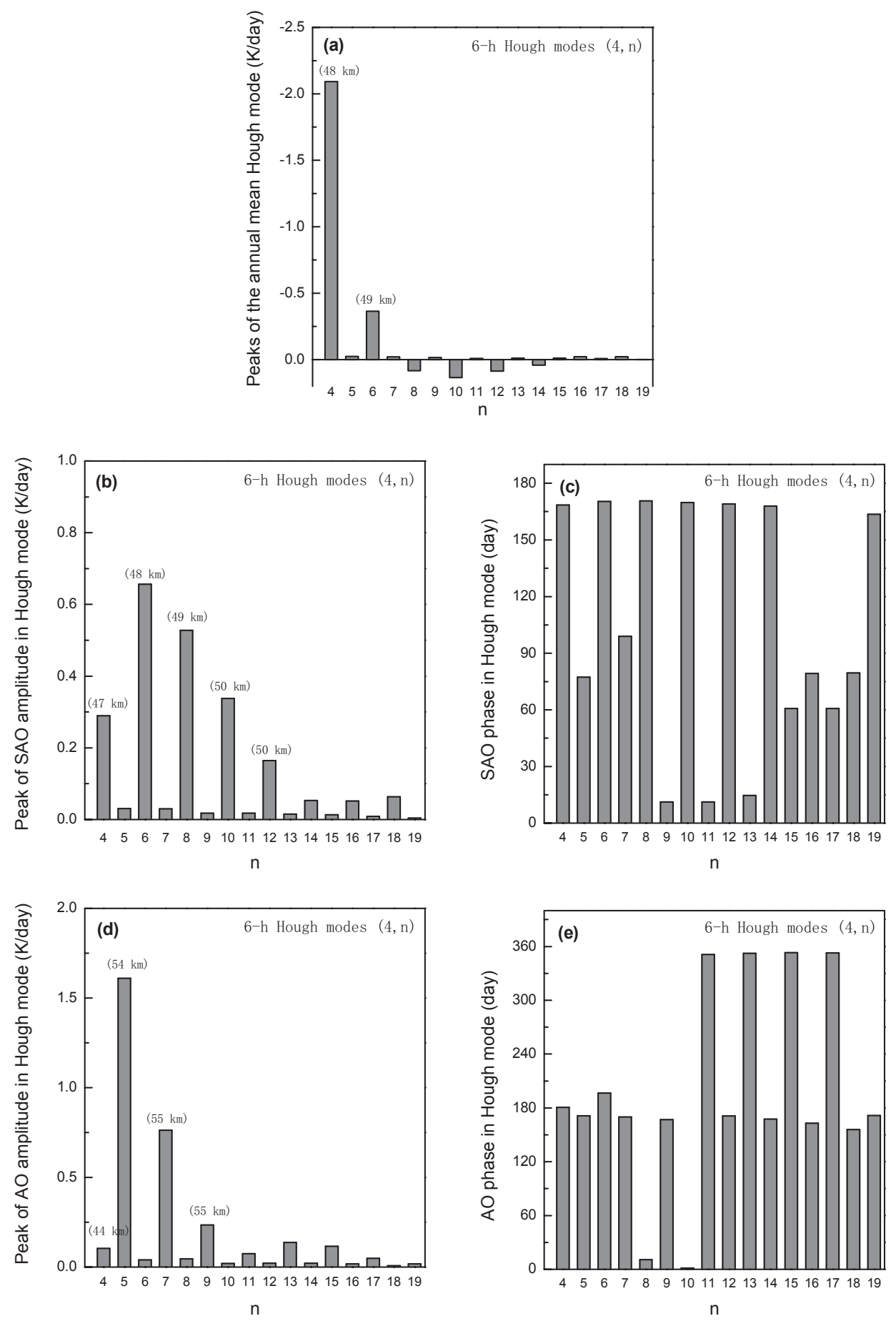

Fig. 18. The same as Fig. 12, but for 6-h Hough modes.

Hough modes. The AO projects almost exclusively onto the asymmetric Hough modes.

\section{Terdiurnal component:}

During the equinox season, the amplitude is positive and symmetric between the two hemispheres.
During the solstice season, the heating rate is stronger in the summer hemisphere than in the winter hemisphere; the maximum heating rate is located near $25^{\circ}$ at the summer stratopause; and the heating rates in the two hemispheres are out of phase. 
Table 1a. The amplitudes (Amp.) $\left(\mathrm{K} \mathrm{day}^{-1}\right)$ and the global averaged vertical wavelength (VWL) (km) of the diurnal heating Hough modes near the peak $(\sim 45 \mathrm{~km})$ at 4 seasons.

\begin{tabular}{llcccccccccc}
\hline & Mode & $(1,-5)$ & $(1,-4)$ & $(1,-3)$ & $(1,-2)$ & $(1,-1)$ & $(1,1)$ & $(1,2)$ & $(1,3)$ & $(1,4)$ & $(1,5)$ \\
\hline Equinox/M & Amp. & 0.10 & 3.99 & 0.17 & 19.42 & 0.28 & 4.31 & - & 1.25 & - & 0.61 \\
& VWL & $\mathrm{E}$ & $\mathrm{E}$ & $\mathrm{E}$ & $\mathrm{E}$ & $\mathrm{E}$ & 28.5 & 16.3 & 11.5 & 8.9 & 7.3 \\
\hline \multirow{2}{*}{ Solstice/JJ } & Amp. & 0.40 & 5.53 & 1.71 & 16.45 & 3.37 & 4.77 & 0.20 & 1.19 & - & 0.61 \\
& VWL & $\mathrm{E}$ & $\mathrm{E}$ & $\mathrm{E}$ & $\mathrm{E}$ & $\mathrm{E}$ & 26.1 & 15.0 & 10.6 & 8.2 & 6.7 \\
\hline \multirow{2}{*}{ Equinox/S } & Amp. & 0.12 & 4.02 & 0.32 & 19.37 & 0.24 & 4.31 & - & 1.18 & - & 0.59 \\
& VWL & $\mathrm{E}$ & $\mathrm{E}$ & $\mathrm{E}$ & $\mathrm{E}$ & $\mathrm{E}$ & 28.6 & 16.4 & 11.5 & 8.9 & 7.3 \\
\hline \multirow{2}{*}{ Solstice/DJ } & Amp. & 0.29 & 5.72 & 1.88 & 16.99 & 3.92 & 5.49 & 0.16 & 1.35 & - & 0.68 \\
& VWL & $\mathrm{E}$ & $\mathrm{E}$ & $\mathrm{E}$ & $\mathrm{E}$ & $\mathrm{E}$ & 24.0 & 13.8 & 9.8 & 7.6 & 6.2 \\
\hline
\end{tabular}

Table 1b. The amplitudes (Amp.) $\left(\mathrm{K} \mathrm{day}^{-1}\right)$ and the global averaged vertical wavelength (VWL) (km) of the semidiurnal heating Hough modes near the peak $(\sim 45 \mathrm{~km})$ at 4 seasons.

\begin{tabular}{lcccccccccccc}
\hline & Mode & $(2,2)$ & $(2,3)$ & $(2,4)$ & $(2,5)$ & $(2,6)$ & $(2,7)$ & $(2,8)$ & $(2,9)$ & $(2,10)$ & $(2,11)$ \\
\hline Equinox/M & Amp. & 6.04 & - & 2.66 & - & 1.52 & - & 1.07 & - & 0.84 & - \\
& VWL & $\mathrm{E}$ & 81.6 & 54.6 & 41.8 & 34.0 & 28.8 & 25.0 & 22.1 & 19.8 & 18.0 \\
\hline \multirow{2}{*}{ Solstice/JJ } & Amp. & 5.48 & 2.33 & 1.65 & 1.56 & 0.73 & 1.11 & 0.26 & 0.81 & 0.21 & 0.63 \\
& VWL & $\mathrm{E}$ & 72.3 & 49.4 & 38.1 & 31.1 & 26.4 & 23.0 & 20.3 & 18.2 & 16.5 \\
\hline Equinox/S & Amp. & 6.03 & - & 2.62 & - & 1.58 & - & 1.08 & - & 0.82 & - \\
& VWL & $\mathrm{E}$ & 82.7 & 55.0 & 42.0 & 34.2 & 28.9 & 25.1 & 22.2 & 19.9 & 18.0 \\
\hline \multirow{2}{*}{ Solstice/DJ } & Amp. & 5.78 & 2.53 & 1.55 & 1.72 & 0.64 & 1.22 & 0.19 & 0.91 & 0.16 & 0.69 \\
& VWL & $\mathrm{E}$ & 64.0 & 44.8 & 34.8 & 28.6 & 24.3 & 21.1 & 18.7 & 16.8 & 15.3 \\
\hline
\end{tabular}

Table 1c. The amplitudes (Amp.) (K day ${ }^{-1}$ ) and the global averaged vertical wavelength (VWL) (km) of the terdiurnal heating Hough modes near the peak $(\sim 52 \mathrm{~km})$ at 4 seasons.

\begin{tabular}{lccccccccccc}
\hline & Mode & $(3,3)$ & $(3,4)$ & $(3,5)$ & $(3,6)$ & $(3,7)$ & $(3,8)$ & $(3,9)$ & $(3,10)$ & $(3,11)$ & $(3,12)$ \\
\hline Equinox/M & Amp. & 3.70 & - & 1.41 & - & 0.66 & - & 0.31 & - & 0.14 & - \\
& VWL & $\mathrm{E}$ & $\mathrm{E}$ & 263.4 & 126.1 & 91.5 & 73.7 & 62.3 & 54.4 & 48.4 & 43.7 \\
\hline \multirow{2}{*}{ Solstice/JJ } & Amp. & 2.97 & 2.03 & 0.25 & 1.14 & 0.51 & 0.59 & 0.51 & 0.21 & 0.35 & - \\
& VWL & $\mathrm{E}$ & $\mathrm{E}$ & 127.6 & 88.1 & 69.4 & 58.0 & 50.0 & 44.2 & 39.7 & 36.1 \\
\hline Equinox/S & Amp. & 3.71 & - & 1.41 & - & 0.70 & - & 0.32 & - & 0.14 & - \\
& VWL & $\mathrm{E}$ & $\mathrm{E}$ & 241.1 & 121.6 & 88.9 & 71.9 & 60.8 & 53.2 & 47.4 & 39.1 \\
\hline \multirow{2}{*}{ Solstice/DJ } & Amp. & 3.06 & 2.11 & 0.26 & 1.21 & 0.60 & 0.59 & 0.56 & 0.19 & 0.37 & - \\
& VWL & $\mathrm{E}$ & $\mathrm{E}$ & 101.9 & 75.2 & 60.7 & 51.4 & 44.7 & 39.7 & 35.8 & 32.6 \\
\hline
\end{tabular}

The annual averaged amplitudes project mainly onto the first two Hough modes. Strong SAOs affect the higherorder terdiurnal symmetric Hough modes. The AO projects exclusively onto the asymmetric Hough mode.

\section{6-h component:}

During the equinox season, the amplitude is negative and symmetric between two hemispheres.

During the solstice season, the heating rate in the winter hemisphere is stronger than in the summer hemisphere; 
Table 1d. The amplitudes (Amp.) $\left(\mathrm{K} \mathrm{day}^{-1}\right)$ and the global averaged vertical wavelength (VWL) (km) of the 6-h heating Hough modes near the peak $(\sim 50 \mathrm{~km})$ at 4 seasons.

\begin{tabular}{llcccccccccc}
\hline & Mode & $(4,4)$ & $(4,5)$ & $(4,6)$ & $(4,7)$ & $(4,8)$ & $(4,9)$ & $(4,10)$ & $(4,11)$ & $(4,12)$ & $(4,13)$ \\
\hline Equinox/M & Amp. & 2.38 & - & 1.02 & - & 0.47 & - & 0.21 & - & - & - \\
& VWL & $\mathrm{E}$ & $\mathrm{E}$ & $\mathrm{E}$ & 231.6 & 136.8 & 103.9 & 85.7 & 73.7 & 65.1 & 58.5 \\
\hline \multirow{2}{*}{ Solstice/JJ } & Amp. & 1.77 & 1.58 & 0.28 & 0.75 & 0.52 & 0.25 & 0.45 & - & 0.24 & 0.15 \\
& $\mathrm{VWL}$ & $\mathrm{E}$ & $\mathrm{E}$ & $\mathrm{E}$ & 128.2 & 96.2 & 78.7 & 67.4 & 59.2 & 53.0 & 48.1 \\
\hline \multirow{2}{*}{ Equinox/S } & Amp. & 2.38 & - & 1.00 & - & 0.51 & - & 0.21 & - & - & - \\
& VWL & $\mathrm{E}$ & $\mathrm{E}$ & $\mathrm{E}$ & 222.6 & 133.6 & 101.8 & 84.1 & 72.4 & 64.0 & 57.5 \\
\hline \multirow{2}{*}{ Solstice/DJ } & Amp. & 1.86 & 1.64 & 0.35 & 0.78 & 0.61 & 0.11 & 0.49 & - & 0.25 & 0.12 \\
& VWL & $\mathrm{E}$ & $\mathrm{E}$ & $\mathrm{E}$ & 101.5 & 80.6 & 67.7 & 58.8 & 52.2 & 47.0 & 42.8 \\
\hline
\end{tabular}

-: less than $0.1 \mathrm{~K} \mathrm{day}^{-1}$; E: Evanescent mode near the peak of the heating.

the maximum heating rate occurs near $20^{\circ}$ at the winter stratopause; and the heating rates in two hemispheres are out of phase.

The annual averaged amplitudes project onto the first two Hough modes, similar to the terdiurnal component. Likewise, the relative importance of SAO variations is higher for higher-order semidiurnal symmetric Hough modes. The AO projects onto the asymmetric Hough modes.

Table 1 summarizes the heating amplitudes of Hough modes for every tidal components near the altitudes of the heating rate peaks for four seasons. For comparison, Table 1 also includes diurnal heating component.

Information about the vertical wavelengths of the different Hough modes is useful for studying tides. We present the vertical wavelengths calculated by the method of Forbes and Vincent (1989). In the calculation, the equivalent depths of the Hough modes are from Flattery (1967) and the distributions of temperature and wind are from the empirical NRMSIS00 and HWM07 models. The vertical wavelength is complex because it depends not only on the equivalent depth of the mode but also on the background distributions of temperature and wind. Therefore, the latitude and altitude distributions of the vertical wavelength are not uniform. A single Hough mode can be a propagating mode at one latitude but a trapped mode in another. The globally averaged vertical wavelengths near the altitude of the peak heating rate for each Hough mode are given in Table 1.
Acknowledgements. We thank the Jet Propulsion Laboratory MLS science team for retrieving and providing the Aura/MLS data. This research was supported by the National Science Foundation of China (41074109, 40921063, 40890165) and the National Important basic Research Project of China (2011CB811405). The project is also supported by the Specialized Research Fund for State Key Laboratories. The National Center for Atmospheric Research is sponsored by the National Science Foundation.

Topical Editor C. Jacobi thanks two anonymous referees for their help in evaluating this paper.

\section{References}

Akmaev, R. A.: Seasonal variations of the terdiurnal tide in the mesosphere and lower thermosphere: a model study, Geophys. Res. Lett., 28, 3817-3820, 2001.

Baldwin, M. P., Gray, L. J., Dunkerton, T. J., Hamilton, K., Haynes, P. H., Randel, W. J., Holton, J. R., Alexander, M. J., Hirota, I., Horinouchi, T., Jones. D. B. A., Kinnersley, J. S., Marquardt, C., Sato, K., and Takahashi, M.: The quasi-biennial oscillation, Rev. Geophys., 39, 179-229, 2001.

Burrage, M. D., Wu, D. L., Skinner, W. R., Ortland, D. A., and Hays, P. B.: Latitude and seasonal dependence of the semidiurnal tide observed by the high-resolution Doppler imager, J. Geophys. Res., 100, 11313-11321, 1995.

Chapman, S. and Lindzen, R. S.: Atmospheric Tides: Thermal and Gravitational, Gordon and Breach, New York, 200 pp., 1970.

Flattery, T. W.: Hough function, Tech. Rep. 21, 175 pp., Dept. Geophys. Sciences, Univ. of Chicago, 1967.

Forbes, J. M. and Garrett, H. B.: Theoretical studies of atmospheric tides, Rev. Geophys. Space, 17, 1951-1981, 1979.

Forbes, J. M. and Vincent, R. A.: Effects of mean winds and dissipation on the diurnal propagating tide: An analytic approach, Planet. Space Sci., 37, 197-209, doi:10.1016/00320633(89)90007-X, 1989.

Groves, G. V.: Hough components of ozone heating, J. Atmos. Terr. Phys., 44, 111-121, 1982a.

Groves, G. V. and Wilson, A.: Diurnal, semi-diurnal and terdiurnal Hough components of surface pressure, J. Atmos. Terr. Phys., 44, 
599-611, 1982b.

Logan, J. A., Jones, D. B. A., Megretskaia, I. A., Oltmans, S. J., Johnson, B. J., Vömel, H., Randel, W. J., Kimani, W., and Schmidlin, F. J.: Quasibiennial oscillation in tropical ozone as revealed by ozonesonde and satellite data, J. Geophys. Res., 108, 4244, doi:10.1029/2002JD002170, 2003.

Manson, A. H., Meek, C. E., Hall, C. M., Nozawa, S., Mitchell, N. J., Pancheva, D., Singer, W., and Hoffmann, P.: Mesopause dynamics from the scandinavian triangle of radars within the PSMOS-DATAR Project, Ann. Geophys., 22, 367-386, doi:10.5194/angeo-22-367-2004, 2004.

Mitchell, N. J., Pancheva, D., Middleton, H., and Hagan, M.: Mean winds and tides in the Arctic mesosphere/lower thermosphere region region and comparison with the GSWM, J. Geophys. Res., 106, A1, doi:10.1029/2001JA900127, 2002.

Miyahara, S. and Forbes, J. M.: Interactions between gravity waves and the diurnal tide in the mesosphere and lower thermosphere, J. Meteorol. Soc. Japan, 69, 523-531, 1991.

Pancheva, D., Mukhtarov, P., and Andonov, B.: Global structure, seasonal and interannual variability of the migrating semidiurnal tide seen in the SABER/TIMED temperatures (2002-2007), Ann. Geophys., 27, 687-703, doi:10.5194/angeo-27-687-2009, 2009.

Randel, W. and Wu, F.: Isolation of the ozone QBO in SAGE II data by singular-value decomposition, J. Atmos. Sci., 53, 2546-2559, 1996.

Schoeberl, M. R., Douglass, A. R., Newman, P. A., Lait, L. R., Lary, D., Waters, J., Livesey, N., Froidevaux, L., Lambert, A., Read, W., Filipiak, M. J., and Pumphrey, H. C.: QBO and annual cycle variations in tropical lower stratosphere trace gases from HALOE and Aura MLS observations, J. Geophys. Res., 113, D05301, doi:10.1029/2007JD008678, 2008.

Smith, A. K.: Structure of the Terdiurnal Tide at $95 \mathrm{~km}$, Geophys. Res. Lett., 27, 177-180, 2000.
Smith, A. K. and Ortland, D. A.: Modeling and Analysis of the Structure and Generation of the Terdiurnal Tide, J. Atmos. Sci., 58, 3116-3134, 2001.

Smith, A. K., Pancheva, D. V., and Mitchell, N. J.: Observations and modeling of the 6-hour tide in the upper mesosphere, J. Geophys. Res., 109, D10105, doi:10.1029/2003JD004421, 2004.

Strobel, D. F.: Parameterization of the atmospheric heating rate from 15 to $120 \mathrm{~km}$ due to $\mathrm{O}_{2}$ and $\mathrm{O}_{3}$ absorption of solar radiation, J. Geophys. Res., 83, 6225-6230, 1978.

Teitelbaum, H., Vial, F., Manson, A. H., Giraldez, R., and Massebeuf, M.: Non-linear interaction between the diurnal and semidiurnal tides: terdiurnal and diurnal secondary waves, J. Atmos. Solar-Terr. Phys., 51, 627-634, 1989.

Xu, J., Smith, A. K., Yuan, W., Liu, H.-L., Wu, Q., Mlynczak, M. G., and Russell III, J. M.: Global structure and long-term variations of zonal mean temperature observed by TIMED/SABER, J. Geophys. Res., 112, D24106, doi:10.1029/2007JD008546, 2007.

Xu, J., Smith, A. K., Liu, H. -L., Yuan, W., Wu, Q., Jiang, G., Mlynczak, M. G., Russell, J. M., and Franke S. J.: Seasonal and quasi-biennial variations in the migrating diurnal tide observed by Thermosphere, Ionosphere, Mesosphere, Energetics and Dynamics (TIMED), J. Geophys. Res., 114, D13107, doi:10.1029/2008JD011298, 2009.

Xu, J., Smith, A. K., Jiang, G., and Yuan, W.: Seasonal variation of the Hough modes of the diurnal component of ozone heating evaluated from Aura Microwave Limb Sounder observations, J. Geophys. Res., 115, D10110, doi:10.1029/2009JD013179, 2010.

Yuan, T., Schmidt, H., She, C. Y., Krueger, D. A., and Reising, S.: Seasonal variations of semidiurnal tidal perturbations in mesopause region temperature and zonal and meridional winds above Fort Collins, Colorado (40.6 $\left.{ }^{\circ} \mathrm{N}, 105.1^{\circ} \mathrm{W}\right)$, J. Geophys. Res., 113, D20103, doi:10.1029/2007JD009687, 2008.

Zhu, X.: An accurate and Efficient Radiation Algorithm for Middle Atmosphere Models, J. Atmos. Sci., 51, 3593-3614, 1994. 